University of Wisconsin Milwaukee

UWM Digital Commons

Theses and Dissertations

August 2017

\title{
Effects of Self-affirmation on Emotion and Cardiovascular Responses
}

Wei-Ju Chen

University of Wisconsin-Milwaukee

Follow this and additional works at: https://dc.uwm.edu/etd

Part of the Biological Psychology Commons

\section{Recommended Citation}

Chen, Wei-Ju, "Effects of Self-affirmation on Emotion and Cardiovascular Responses" (2017). Theses and Dissertations. 1595.

https://dc.uwm.edu/etd/1595

This Dissertation is brought to you for free and open access by UWM Digital Commons. It has been accepted for inclusion in Theses and Dissertations

by an authorized administrator of UWM Digital Commons. For more information, please contact open-access@uwm.edu. 


\title{
EFFECTS OF SELF-AFFIRMATION OF EMOTION AND CARDIOVASCULAR RESPONSES
}

\author{
by
}

Wei-Ju Chen

A Dissertation Submitted in
Partial Fulfillment of the
Requirements for the Degree of

Doctor of Philosophy

in Psychology

at

The University of Wisconsin-Milwaukee

August 2017 


\title{
ABSTRACT \\ EFFECTS OF SELF-AFFIRMATION OF EMOTION \\ AND CARDIOVASCULAR RESPONSES
}

by

\author{
Wei-Ju Chen
}

The University of Wisconsin-Milwaukee, 2017

Under the Supervision of Professor Raymond Fleming, Ph.D.

Self-affirmation is the act of focusing on important aspects of the self, such as personal values and characteristic. Benefits of self-affirmation have been documented in past research. However, the immediate impacts of self-affirmation on cardiovascular responses have not been fully explored. Therefore, the present study examined such effects both during and consequent to the practice of self-affirmation. One hundred and twenty-five participants completed the study. A within-subject design was used, in which each participant went through both the control and selfaffirmation conditions (the order of presentation was counterbalanced). In the self-affirmation condition, participants were asked to write about their top-ranked personal value for 5 minutes, whereas a writing exercise unrelated to personal values was used in the control condition. After each writing exercise, the International Affective Picture System (IAPS) was used to induce positive and negative emotion. Cardiovascular measures and self-reported affective responses were collected throughout the experiment. Results showed that self-affirmation produced lower cardiovascular arousal, less negative affect, and higher levels of self-worth. Compared to the control condition, when practicing self-affirmation, participants had higher high frequency component of heart rate variability (HF-HRV) and respiratory sinus arrhythmia (RSA). During negative emotion induction, self-affirmation also led to lower maximum heart rate, higher RSA, and lower ratings of negative affect. Moreover, affirmational thinking was found to be associated with self-resources such as self-esteem, optimism, and one's perceived worthiness in a group. 
These findings suggest that the act of focusing on an important aspect of self has beneficial effects on psychological and physiological well-being. The present study is one of the few that have examined self-affirmation's impacts on vagal tone using HF-HRV, RSA, and direct manipulation of emotion. Not only has self-affirmation shown to be valuable, its positive effects appear quickly, and it is easy to practice with low to no cost. 
(C) Copyright by Wei-Ju Chen, 2017 All Rights Reserved 


\section{TABLE OF CONTENTS}

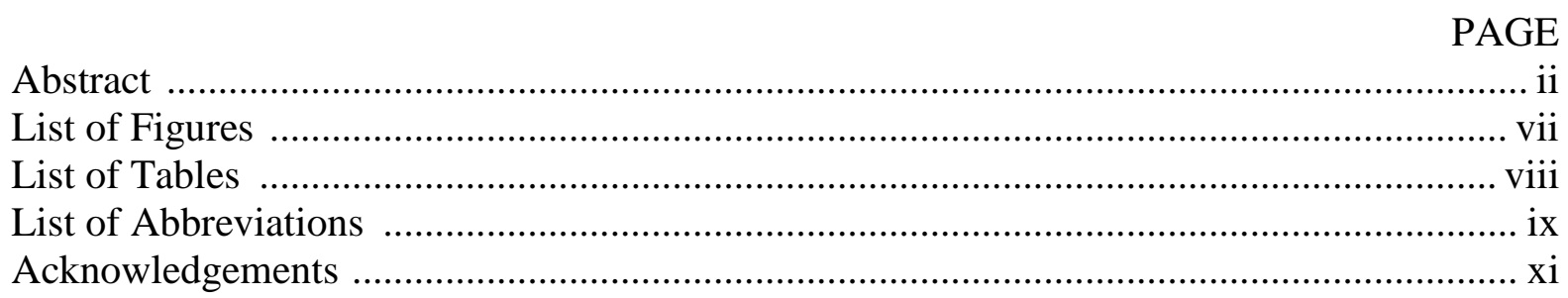

\section{CHAPTER}

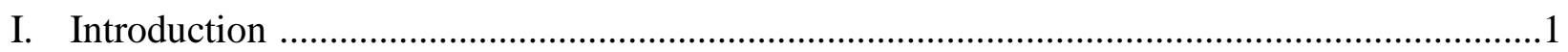

Background of Self-Affirmation ...................................................................................

Self-Affirmation and Psychological Well-Being ...............................................

Self-Affirmation and Physiological Responses ..................................................

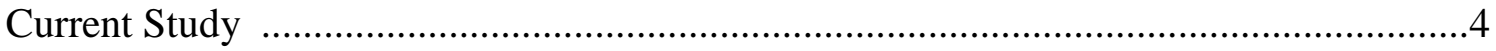

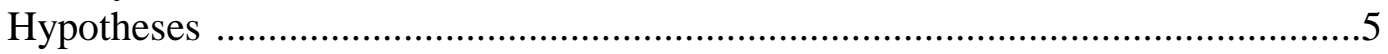

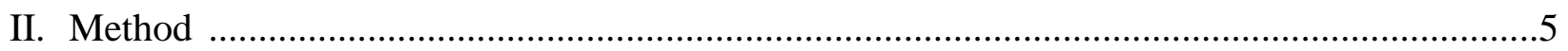

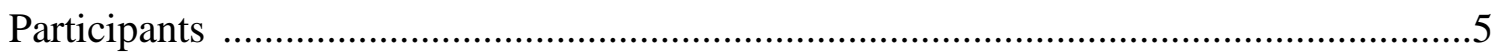

Self-Affirmation Manipulation ...............................................................................6

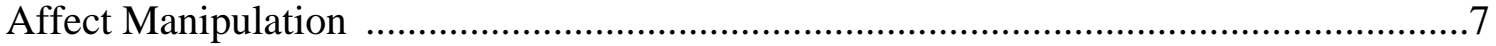

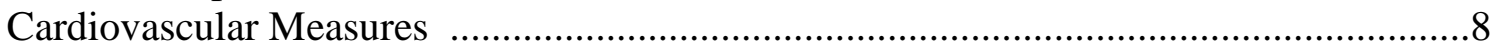

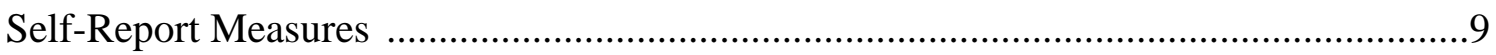

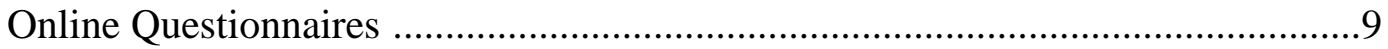

Cardiovascular Health History Questionnaire …………….......................9

Rosenberg Self-Esteem Scale ………………………..........................9

Collective Self-Esteem Scale …………..............................................10

Revised Life Orientation Test ............................................................10

How I See Myself ................................................................................11

Brief Resilience Scale ……………………………………………....11

Depression Anxiety Stress Scale …………………………………........12

Perspective and Affirmational Thinking Questionnaire ...........................12

Demographic Questionnaire ..................................................................13

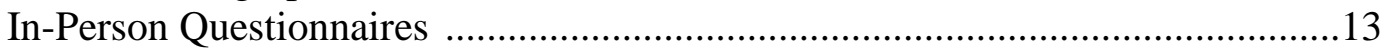

Self-Assessment Manikin ....................................................................13

Positive and Negative Affect Schedules ...................................................13

Brunel Mood Scale ...............................................................................14

Self-Worth Questionnaire .........................................................................

Post-Writing Exercise Questionnaire ...………………………………....15

IAPS Task Related Perceived Stress Questionnaire ..................................15

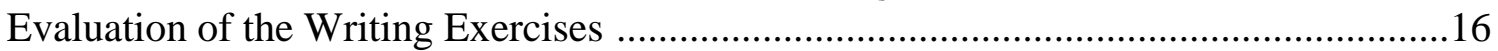

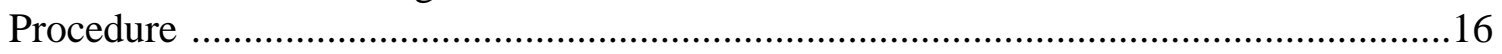




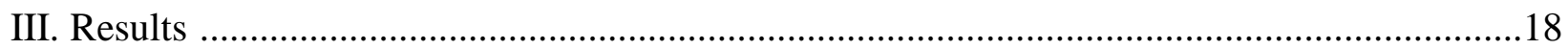

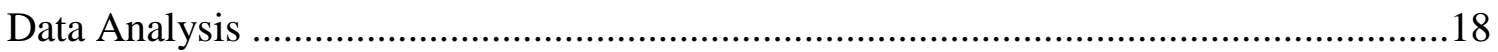

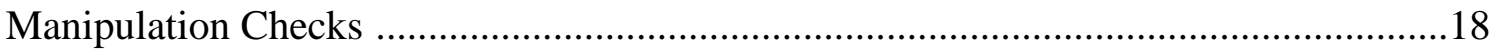

Affect Manipulation Check ………………………........................................18

Self-Affirmation Manipulation Check …………………................................19

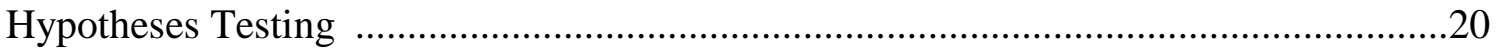

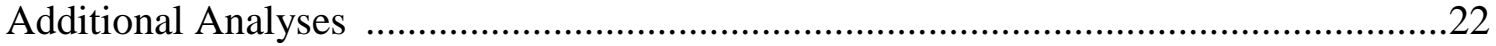

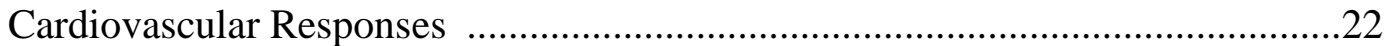

Positive and Negative Affect .........................................................................24

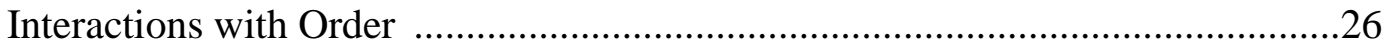

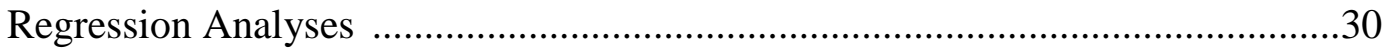

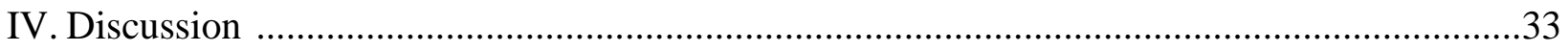

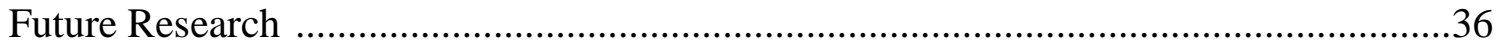

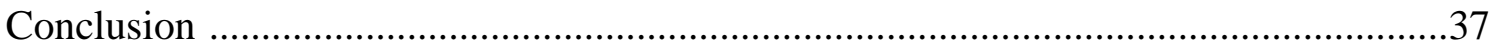

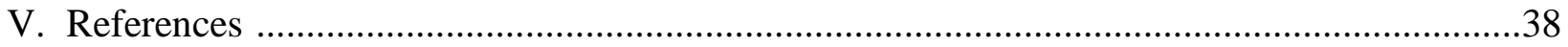

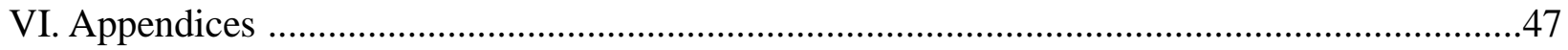

Appendix A. Sources of Validation Scale ……………….........................................47

Appendix B. Value Affirmation Writing Exercise ………….........................................48

Appendix C. Jelly Bean Flavor Scale ..........................................................................49

Appendix D. Jelly Bean Writing Exercise ……………………………………….....50

Appendix E. Examples of International Affective Picture System (IAPS) Images .........51

Appendix F. Self-Assessment Manikin (SAM) ………….............................................52

Appendix G. Cardiovascular Health History Questionnaire …………….........................53

Appendix H. Rosenberg Self-Esteem Scale (RSES) ……….......................................56

Appendix I. Collective Self-Esteem Scale (CSES) …………......................................57

Appendix J. Revised Life Orientation Test (LOT-R) ...................................................59

Appendix K. How I See Myself (HSM) ...............................................................6

Appendix L. Brief Resilience Scale (BRS) ……………............................................61

Appendix M. Depression Anxiety Stress Scale-21 (DASS-21) ......................................62

Appendix N. Perspective and Affirmational Thinking ..................................................64

Appendix O. Demographic Questionnaire .................................................................66

Appendix P. Positive and Negative Affect Schedules (PANAS) .....................................67

Appendix Q. Brunel Mood Scale (BMS) ................................................................68

Appendix R. Self-Worth Questionnaire (SWQ) ..........................................................69

Appendix S. Post-Writing Exercise Questionnaire ………………………………….....70

Appendix T. IAPS Task Related Perceived Stress Questionnaire ...................................71

Appendix U. Evaluation of the Writings ........................................................................72

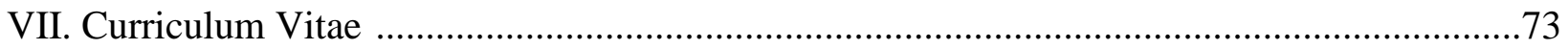




\section{LIST OF FIGURES}

Figure 1. Procedural Timeline for the Experiment …........................................................17

Figure 2. Interaction Effect for Average Heart Rate During Writing Exercises .......................26

Figure 3. Interaction Effect for Positive Affect After Writing Exercises ................................27

Figure 4. Interaction Effect for Positive Affect After Image Presentations ..............................27

Figure 5. Interaction Effect for Vigor After Image Presentations ......................................27 


\section{LIST OF TABLES}

Table 1. Demographic Characteristics of the Participants ........................................................6

Table 2. Descriptive Statistics of Valence Scores for the Images ..........................................19

Table 3. Descriptive Statistics for Self-Affirmation Manipulation Check …...........................20

Table 4. Descriptive Statistics for Hypotheses Testing ...................................................21

Table 5. Descriptive Statistics for Cardiovascular Responses in Additional Analyses ...............23

Table 6. Descriptive Statistics for Positive and Negative Affect in Additional Analyses ...........25

Table 7. Descriptive Statistics for Interactions with Order of the Conditions ..........................28

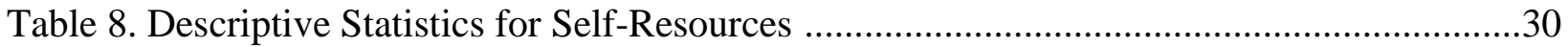

Table 9. Results of Multiple Regression Analyses Using Self-Resources as Predictors ..............31 


\section{LIST OF ABBREVIATIONS}

\begin{tabular}{|c|c|}
\hline ANCOVA & Analysis of Covariance \\
\hline ANOVA & Analysis of Variance \\
\hline B-H & Benjamini-Hochberg \\
\hline BMS & Brunel Mood Scale \\
\hline BRS & Brief Resilience Scale \\
\hline $\mathrm{CI}$ & Confidence Interval \\
\hline CSES & Collective Self-Esteem Scale \\
\hline DASS-21 & Depression Anxiety Stress Scale-21 \\
\hline DBP & Diastolic Blood Pressure \\
\hline ECG & Electrocardiography \\
\hline FDR & False Discovery Rate \\
\hline $\mathrm{HF}$ & High Frequency \\
\hline HF-HRV & High Frequency Component of Heart Rate Variability \\
\hline HPA & Hypothalamic-Pituitary-Adrenocortical \\
\hline HR & Heart Rate \\
\hline $\mathrm{hr}$ & Hour(s) \\
\hline HRV & Heart Rate Variability \\
\hline HSM & How I See Myself \\
\hline IAPS & International Affective Picture System \\
\hline ITI & Intertrial Interval \\
\hline LOT-R & Revised Life Orientation Test \\
\hline
\end{tabular}




$\begin{array}{ll}\text { min } & \text { Minute(s) } \\ \text { mmHg } & \text { Millimeter of Mercury } \\ \text { NA } & \text { Negative Affect } \\ \text { PA } & \text { Positive Affect } \\ \text { PANAS } & \text { Positive and Negative Affect Schedules } \\ \text { RSA } & \text { Respiratory Sinus Arrhythmia } \\ \text { RSES } & \text { Rosenberg Self-Esteem Scale } \\ \text { S } & \text { Second(s) } \\ \text { SAM } & \text { Self-Assessment Manikin } \\ \text { SBP } & \text { Systolic Blood Pressure } \\ \text { SD } & \text { Standard Deviation } \\ \text { SE } & \text { Standard Error } \\ \text { SWQ } & \text { Self-Worth Questionnaire } \\ \text { UWM } & \text { University of Wisconsin-Milwaukee }\end{array}$




\section{ACKNOWLEDGEMENTS}

The completion of this dissertation would not have been possible without the support of many people in my life. First and foremost, I would like to express my deepest gratitude to Dr. Raymond Fleming, my advisor and mentor, for his guidance, patience, and support. I am also grateful for the opportunities and challenges Ray has offered me, allowing me not only to learn and improve academically, but also to achieve my personal growth. It has truly been an honor for me to work with such an inspiring and caring mentor. I would also like to thank the rest of my dissertation committee, Dr. Diane Reddy, Dr. Susan Lima, Dr. Han Joo Lee, and Dr. Shawn Cahill, for their insightful comments and warm encouragement. Furthermore, my sincere thanks goes to all the research assistants and lab members with whom I have had the pleasure to work in Dr. Fleming's Emotion, Stress, and Coping Research Laboratory. The data collection and findings of the present study could not be accomplished without their diligence, devotion of time, and helpful feedback. Lastly, I would like to show my great appreciation to my family and friends, who have given me assistance, motivation, strength, and love along the way. 


\section{Introduction}

The sense and perception of self is important; people have the need to feel adequate about themselves. Self-affirmation is a method of coping or psychological adaption that helps people restore self-integrity and lower distress when facing stressful or threatening events (Steele, 1988; Cohen \& Sherman, 2014; Sherman, 2013). Much effort and time have been devoted to selfaffirmation research over the past three decades, and the beneficial effects of self-affirmation have been well-documented. Affirming one's own important values or positive personal characteristics can buffer against stress (e.g., Creswell et al., 2005; Keough \& Markusm, 1998), facilitate adaptation in threatening situations by reducing defensive responses (e.g., Harris, Mayle, Mabbott, \& Napper, 2007; Sherman \& Cohen, 2006), decrease achievement gaps and improve academic performance in minority students (e.g., Cohen, Garcia, Purdie-Vaughns, Apfel, \& Brzustoski, 2009; Miyake et al., 2010), and increase acceptance of health messages as well as promote healthy behaviors (e.g., Harris et al., 2014; Harris \& Napper, 2005). Nevertheless, relative few studies have focused on the effects on physiological reactivity or on responses during self-affirmation. Moreover, direct manipulation of affect has rarely been used, and emotion has often been assessed as a moderator or a mediator (as opposed to a dependent variable). Therefore, the present study aims to provide more insight on the immediate effects of self-affirmation on emotion and cardiovascular reactivity, both during and consequent to the practice of self-affirmation.

\section{Background of Self-Affirmation}

Self-affirmation theory, first proposed by Steele (1988), posits that people are motivated to protect their self-integrity and maintain their sense of adequacy and self-worth. Self-integrity is defined as one's perception of oneself as being capable, good, and appropriate (Cohen \& 
Sherman, 2014; Sherman, 2013; Sherman \& Cohen, 2006; Sherman et al., 2013). When

encountering a stressful or threatening event, people's defense mechanism is activated to protect their self-integrity and to adapt to the threatening situation. Some direct psychological defensive responses include avoidance, denial, and rationalization; however, these can be maladaptive. Self-affirmation theory suggests an indirect method of psychological adaptation; one can respond to the stressor or threatening information by affirming a value or self-resource unrelated to the event. Through such self-affirmation, one focuses on other aspects of self-integrity, realizing that his/her sense of self and self-worth is independent of the impacts of the present threatening situation. Self-affirmation reduces defense mechanisms and one's need to deny or rationalize the threat, yielding to self-integrity protection and lower stress responses (Ruiter, 2011; Sherman, 2013; Sherman \& Cohen, 2006).

Self-affirmation and psychological well-being. Self-affirmation is an act that involves focusing on important aspects of self to restore or sustain one's perception of adequacy. Research in this area typically ask participants to affirm their core values or positive personal characteristics (Epton, Harris, Kane, van Koningsbruggen, \& Sheeran, 2015; McQueen \& Klein, 2006; Ruiter, 2011; Steele \& Liu, 1983). Past research studies have demonstrated the beneficial effects of self-affirmation. For instance, self-affirmation can buffer against stress. In the study of Keough (as cited in Keough \& Markusm, 1998), she asked participants to focus on either their most or least important personal value prior to performing a stress task. Results showed that participants who affirmed themselves using their most important value reported lower perceived stress, greater feelings of self-worth, and higher levels of state self-esteem, compared to the group that focused on the least important value. In a separate longitudinal field study, Keough (as cited in Taylor \& Sherman, 2008) found that college students in the self-affirmation 
condition reported lower stress levels and fewer physical illness symptoms over time compared to the control groups. These findings showed that self-affirmation serves as a stress buffer.

Past research has also demonstrated the buffering effects of self-affirmation against negative emotions. Liu and Steele (1986) exposed participants to no-, low-, or high-helplessness and found that self-affirmation eliminated the negative mood induced by the helplessness training. In a different study conducted by Galinsky, Stone, and Cooper (2000), they examined the role of self-affirmation in the effects of dissonance on affect. It was found that selfaffirmation produced less negative affect and the least psychological discomfort. Similar effects can also be seen in Van den Bos' (2001) study, in which the induction of mortality salience and fairness manipulation were used. Van den Bos found that self-affirmed participants showed less negative affect in response to the tasks.

The effects of self-affirmation on positive emotions, however, have not been clearly demonstrated in past research. Some researchers have suggested positive affect as a possible underlying mechanism or mediator of self-affirmation (e.g., Tesser, 2000). However, Steele and Liu (1983) argued against this, as positive mood induction did not yield the same effects as selfaffirmation. In measuring positive mood as a dependent variable, the study of Koole, Smeets, van Knippenberg, and Dijksterhuis (1999) was one of the few that examined this link between self-affirmation and positive affect; they implemented an implicit mood test and found that selfaffirmed individuals showed more positive affect. Other studies have suggested selfaffirmation's beneficial effects on variables related to positive emotions, such as compassion (Lindsay \& Creswell, 2014), love and connection (Crocker, Niiya, \& Mischkowski, 2008).

Self-affirmation and physiological responses. Researchers in this field have examined not only self-reported perceived stress levels; physiological stress reactivity has also been studied 
in its relation to self-affirmation. Creswell et al. (2005) assessed the impacts of self-affirmation on neuroendocrine responses to an acute stressor (the Trier Social Stress Task) and found that self-affirmed participants showed significantly lower cortisal reactivity compared to those in the control group. Sherman, Bunyan, Creswell, and Jaremka (2009) also observed how selfaffirmation affects physiological stress responses using a longitudinal study. They recruited college students and analyzed their urinary catecholamines in response to midterm examinations (naturalistic stressors). Results showed that self-affirmed students had a lower level of epinephrine compared to the control group. These findings suggest the mitigation of selfaffirmation on hypothalamic-pituitary-adrenocortical (HPA) activation and sympathetic nervous system reactivity to stress.

A few studies have also examined cardiovascular reactivity in self-affirmation research. Creswell et al. (2005) did not find a significant difference in heart rate (HR) and blood pressure in response to the Trier Social Stress Task between the self-affirmation condition and control group. However, Tang and Schmeichel (2015) reported the beneficial effects of self-affirmation on cardiovascular recovery. To induce self-threat, participants in this study received either a neutral or insulting evaluative feedback. Those who were self-affirmed showed shorter recovery rate in mean arterial pressure. In addition, among participants who received insulting feedback, self-affirmed individuals had lower HR across time.

\section{Current Study}

Although there has been much research on self-affirmation, few studies have focused on physiological responses. Only two studies have assessed cardiovascular reactivity in this area of research, and neither of these studies observed the cardiovascular responses during selfaffirmation. Furthermore, no studies have included physiological measures in examining the 
association between self-affirmation and emotion. Therefore, the present study sought to provide more insights on the role of cardiovascular reactivity in the effects of self-affirmation and emotion.

The present study utilized a within-subject design. All participants completed both selfaffirmation and control writing exercises in the experiment, which was followed by affect manipulation. Not many studies have used direct manipulation of emotions in assessing selfaffirmation; thus, the International Affective Picture System (IAPS; Lang, Bradley, \& Cuthbert, 2005) was used to induce positive and negative affective responses. Self-report measures of emotions were administered after writing exercises, during as well as after the presentation of IAPS image sets. Cardiovascular measures, including HR, respiration, and blood pressure, were recorded throughout the experiment to assess the effects of self-affirmation on physiological responses.

Hypotheses. It was hypothesized that participants would show lower cardiovascular arousal to negative images (lower average HR, lower maximum HR, and greater respiratory sinus arrhythmia [RSA]) in the self-affirmation condition than in the control condition. It was also predicted that recovery rates of HR would be shorter after presentations of negative images when one was self-affirmed compared to the control condition. Furthermore, it was hypothesized that the self-affirmation condition would produce lower ratings of negative affect during negative image presentations, and after IAPS image presentations, compared to the control condition.

\section{Method}

\section{Participants}

The online Sona system, in-class announcement, and flyers were used to recruit college students at University of Wisconsin-Milwaukee (UWM). No particular interest or restriction in 
gender, ethnicity, or major was demonstrated during recruitment. Because cardiovascular responses were measured in this study, to ensure the accuracy of the physiological data, prospective participants who had severe cardiovascular or respiratory problems (e.g., coronary artery disease, stroke, myocardial infarction) were excluded from the study. The present study consisted of a final sample size of 125 participants. The means age was 22.90 years $(S D=6.09)$. Table 1 shows the demographic information of the participants.

Table 1 Demographic Characteristics of the Participants

\begin{tabular}{lcc}
\hline Variable & & \\
\hline Gender & $n=98$ & $78.4 \%$ \\
$\quad$ Female & $n=27$ & $21.6 \%$ \\
$\quad$ Male & & \\
\hline Ethnicity & $n=81$ & $64.8 \%$ \\
$\quad$ White/Caucasian (Non-Hispanic) & $n=11$ & $8.8 \%$ \\
$\quad$ Hispanic/Latino & $n=11$ & $8.8 \%$ \\
Asian/Pacific Islander & $n=10$ & $8.0 \%$ \\
$\quad$ Biracial/Multiracial & $n=7$ & $5.5 \%$ \\
Black/African American & $n=5$ & $4.0 \%$ \\
$\quad$ Other & & \\
\hline Year in College & $n=37$ & $29.6 \%$ \\
Senior & $n=31$ & $24.8 \%$ \\
$\quad$ Junior & $n=25$ & $20.0 \%$ \\
Sophomore & $n=23$ & $18.4 \%$ \\
Freshman & $n=5$ & $4.0 \%$ \\
Other & $n=4$ & $3.2 \%$ \\
Graduate Student & & \\
\hline
\end{tabular}

Note. $N=125$.

\section{Self-Affirmation Manipulation}

The self-affirmation manipulation used in this study was based on the description and protocol of the previous research (Charlson et al., 2007; Cohen, Aronson, \& Steele, 2000; Ruiter, 2012; Sherman, Nelson, \& Steele, 2000). As the current study used a within-subject design, each 
participant went through both the no self-affirmation (control) condition and the self-affirmation condition. During the self-affirmation condition, participants ranked the 11 values listed in Harber's (1995) Source of Validation Scale (Appendix A). The experimenter then administered a 5-min writing exercise regarding their top-ranked value. Participants were asked to write about why their top-ranked value is important to them and describe instances when it made them feel good about themselves (see Appendix B for the instruction).

For the control task, participants were asked to rank 11 different jelly bean flavors (Lannin, 2012) and to write about their third- and fourth-ranked jelly bean flavors for 5 min (Appendices C and D). This procedure was used in the previous studies as a content-unrelated control task (Critcher, Dunning, \& Armor, 2010; Lannin, 2012). Other research asked participants to write about their lowest ranked value; however, Cohen et al. (2000) argued that such writing may still become self-affirming in the process, and thus is not an appropriate control task. The order of control and self-affirmation tasks was counterbalanced.

\section{Affect Manipulation}

After the control and self-affirmation tasks, participants were asked to view a series of positive, negative, and neutral images from the International Affective Picture System (IAPS; Lang et al., 2005; examples of the pictures are shown in Appendix E), which is a standardized method utilized to induce emotions. The Self-Assessment Manikin (SAM) was used to measure participants' perceived valence, arousal, and dominance (Bradley \& Lang, 1994; Lang, 1980; Lang et al., 2005; Appendix F). The affect manipulation procedure took place on a desktop computer via SuperLab 4.5 software (Cedrus Corporation, San Pedro, CA). Prior to the presentation of each picture, a tone was presented to inform the participants a picture was going to appear soon and direct their attention to the screen. A picture was displayed $6 \mathrm{~s}$ after the tone; 
it stayed on the screen for $6 \mathrm{~s}$ and was followed by a $16 \mathrm{~s}$ intertrial interval (ITI) during which SAM was administered for the participants to rate the image. After the ITI, the next trial would begin with a tone again. Each picture set consisted of 10 positive, 10 negative, and 10 neutral images, and it took 14 min to complete 30 pictures. Participants viewed two sets of images in the experiment: one after the control task and the other one after the self-affirmation manipulation. A practice trial with two neutral images took place before the first IAPS task. The order of the image set presentations was counterbalanced.

\section{Cardiovascular Measures}

Participants' HR, respiration, and blood pressure were recorded throughout the experiment as they are cardiovascular indicators of stress and changes in the autonomic nervous system. These measures (except respiration) are consistent with Creswell et al. (2005) and Tang and Schmeichel (2015) in assessing effects of self-affirmation on stress. HR (via electrocardiography [ECG]) and respiration were assessed using Biopac MP 35 Acquisition Unit (Biopac Systems, Inc., Santa Barbara, CA), whereas an automatic digital blood pressure monitor was utilized to examine blood pressure (measured in $\mathrm{mmHg}$ ). Blood pressure is affected by the sympathetic nervous system; constriction of blood vessels and increased systolic blood pressure reflect sympathetic stimulation (Bradley, 2000; Guyenet, 2006). Both systolic blood pressure (SBP) and diastolic blood pressure (DBP) were collected six times during the experiment: at the initial baseline, immediately after the two writing exercises and the two IAPS image presentations, as well as during the final baseline at the end of the experiment. Furthermore, upon the completion of data collection, RSA, the variation in HR linked to the respiration cycle, was computed from ECG data and respiration as it reflects the vagal tone (Butler, Wilhem, \& Gross, 2006). Moreover, as a part of the additional exploratory analyses, Kubios heart rate 
variability (HRV) analysis software (MATLAB, Finland) was used to examine high-frequency (HF) components of HRV, as HF-HRV is also an index of parasympathetic activity (Appelhans \& Luecken, 2006).

\section{Self-Report Measures}

Online questionnaires. Several questionnaires were administered online before participants were recruited for the in-person experiment. Studies have found that self-affirmation is associated with some trait characteristics and an individual's resources, such as self-esteem (Creswell et al., 2005; Koole et al., 1999; McQueen \& Klein, 2006; Sherman \& Cohen, 2006; Sherman \& Kim, 2005). Therefore, data on self-resources were collected. Furthermore, these online questionnaires collected participants' basic demographic information and health history, which served as online screening. Completing all the online questionnaires took approximately 30 min.

Cardiovascular Health History Questionnaire. To ensure the accuracy of the physiological data recorded in the experiment, prospective participants' cardiovascular health history (Appendix G) was collected and served as an online screening. Those who had severe cardiovascular or respiratory problems (e.g., coronary artery disease, stroke, myocardial infarction, asthma) or who had been taking medications such as beta-blockers were not recruited for the in-person experiment.

Rosenberg Self-Esteem Scale. The Rosenberg Self-Esteem Scale (RSES; Rosenberg, 1989; Appendix H) is a 10-item measure on global self-evaluation or attitude about self. Participants were asked to rate each statement on a 4-point Likert-type scale (ranging from "strongly agree" to "strongly disagree"). Examples of the items include "on the whole, I am satisfied with myself" and "I feel that I'm a person of worth, at least on an equal plane with 
others." Five items needed to be reversed coded, and a total self-esteem score was then computed by summing the scores on all items; high scores represent high self-esteem. The RSES has been widely used in social sciences research. It is valid and reliable (Gray-Little, Williams, \& Hancock, 1997; Robins, Hendin, \& Trzesniewski, 2001). The Cronbach's $\alpha$ coefficient for the RSES was .87 in the present study.

Collective Self-Esteem Scale. The Collective Self-Esteem Scale (CSES; Luhtanen \& Crocker, 1992; Appendix I) is a 16-item questionnaire that examines a group-level self-esteem (rather than the individualistic or personal self-esteem measured by the RSES). The CSES consists of four dimensions: (a) the Membership subscale focuses on one's perception of one's worthiness as a group member (e.g., "I am a worthy member of the social group I belong to"); (b) the Private subscale measures the perceived quality of one's social groups (e.g., "I feel good about the social groups I belong to"), (c) the Public subscale assesses how one thinks other people see one's social groups (e.g., "in general, others respect the social groups that I am a member of"); and (d) the Identity subscale examines the extent to which one identifies with the social groups (e.g., "the social groups I belong to are an important reflection of who I am"). Each statement was rated on a 7-point Likert-type scale, ranging from "strongly disagree" to "strongly agree.” The CSES is a valid and reliable measure (Luhtanen \& Crocker, 1992; Sherman \& Kim, 2005). An overall Cronbach's $\alpha$ of .92 was found for the CSES in the present study (Membership $=.85$, Private $=.84$, Public $=.77$, and Identity $=.70)$.

Revised Life Orientation Test. The Revised Life Orientation Test (LOT-R; Scheier, Carver, \& Bridges, 1994; Appendix J) aims to assess dispositional optimism. It consists of 10 items that are rated on a 5-point Likert-type scale, ranging from "strongly disagree" to "strongly agree". Examples of the statements are "in uncertain times, I usually expect the best" and 
"overall, I expect more good things to happen to me than bad." Three pessimistic items (e.g., "if something can go wrong for me, it will") needed to be reversed coded, and a total score was obtained by summing six of the items, as there are four fillers. The LOT-R has demonstrated a good validity and reliability (Creswell et al., 2005; Scheier et al., 1994). The Cronbach's $\alpha$ for LOT-R in the present study was .79.

How I See Myself. The How I See Myself questionnaire (HSM; Tayler \& Gollwitzer, 1995; Appendix K) is a 22-item questionnaire that measures self-enhancement. The questionnaire contains 11 positive qualities (e.g., "cheerful," "sensitive to others") and 11 negative qualities (e.g., "cranky," "lacking motivation"). Participants were asked to rate themselves on a 7-point Likert-type scale in comparison to other UWM college students. The scale ranges from "much worse" to "much better" than the average college students of the participants' age and gender. The negatively worded items were reversed coded, and a total selfenhancement score was obtained by summing all scores on the scale. The HSM is valid and reliable (Creswell et al., 2005; Taylor et al., 2008; Tayler \& Gollwitzer, 1995; Taylor, Lerner, Sherman, Sage, \& McDowell, 2003; Thomsen, Sidanius, \& Fiske, 2007). In the present study, the Cronbach's $\alpha$ coefficients for the positive and negative items were .86 and .78 respectively.

Brief Resilience Scale. The Brief Resilience Scale (BRS; Smith et al., 2008; Appendix L) is a 6-item questionnaire that examines people's resilience, which is the ability to recover from stress. Participants were asked to respond to the statements using a 5-point Likert-type scale, ranging from "strongly disagree" to "strongly agree." Examples of the items are "I tend to bounce back quickly after hard times" and "it does not take me long to recover from a stressful event." Each participant's resilience score was calculated by reverse coding three items and obtaining a mean for all the items on the scale; higher scores represent higher resilience. The 
BRS has a good validity and reliability (Breslow et al., 2015; Smith et al., 2008). A Cronbach's $\alpha$ of .87 was found for the BRS in the present study.

Depression Anxiety Stress Scale. The Depression Anxiety Stress Scale-21 (DASS-21;

Lovibond \& Lovibond, 1995; Appendix M) is a 21-item scale that aims to assess levels of psychological distress. The DASS-21 consists of three valid and reliable dimensions:

Depression, Anxiety, and Stress. Examples of the items include "I felt down-hearted and blue" for the Depression subscale, "I felt scared without any good reason" for Anxiety, and "I found it difficult to relax" for Stress. Participants were asked to rate how each statement applies to them in general (as opposed to over the past week in the original scale) using a 4-point Likert-type scale. Three scores were computed for the three subscales by summing the items that fall into each category and multiplied the sums by two, as the DASS-21 is a short version of the scale (Lovibond \& Lovibond, 1995). An overall Cronbach's $\alpha$ coefficient of .91 was found for the DASS-21 in the present study $($ Depression $=.86$, Anxiety $=.78$, and Stress $=.81)$.

Perspective and affirmational thinking questionnaire. The study was designed to examine how often participants affirmed themselves and showed perspective thinking in real life, as such thoughts may be associated with the outcome measures of the present study. Fourteen items (Appendix N) were used to assess affirmational (e.g., "I affirm my worth as a person") and perspective (e.g., "I appreciate I have multiple parts of who I am") thinking. Participants were asked to rate each statement using a 7-point Likert-type scale, ranging from "never" to "all the time." This questionnaire is a revised version of the one distributed in Critcher and Dunning (2015). In the present study, perspective thinking subscale showed a Cronbach's $\alpha$ of .93, and affirmational thinking subscale had a Cronbach's $\alpha$ of .87 . 
Demographic questionnaire. A demographic questionnaire (Appendix O) was administered to collect participants' basic demographic information, including age, gender, year in college, major, and race.

In-person questionnaires. Several questionnaires were administered during the experiment to obtain state characteristics, such as participants' affective state, stress levels, and feelings of self-worth.

Self-Assessment Manikin. The Self-Assessment Manikin (SAM; Bradley \& Lang, 1994; Lang, 1980; Lang et al., 2005; Appendix F), a standardized affective rating system, was administered during the $16 \mathrm{~s}$ ITIs to measure participants' perceived valence, arousal, and dominance for each image. The SAM used in this study consisted of 9-point Likert-type scale with graphic figures that reflect the corresponding value or responses. The ranges of the scales for the three dimensions are from "positive" to "negative" for valence, from "excited" to "calm" for arousal, and from "loss of control" to "in control" for dominance. It has been validated and has shown high internal consistency as well as split-half coefficients ranging from $r=.93$ to .94 (Lang et al., 2005; Morris, 1995).

Positive and Negative Affect Schedules. The Positive and Negative Affect Schedules (PANAS; Watson, Clark, \& Tellegen, 1988; Appendix P) was administered five times throughout the experiment: before the initial baseline, after the two writing exercises, and after both sets of IAPS images. The PANAS consists of 10 positive (e.g., "interested," "enthusiastic") and 10 negative (e.g., "distressed," "ashamed") items rated on a 5-point Likert-type scale, ranging from "not at all" to "extremely." Two scores were computed for the positive affect (PA) and negative affect (NA) subscales by summing the items in each category. The purpose of using the PANAS was to assess participants' momentary positive and negative affect at the 
baseline as well as after self-affirmation and affect manipulation. The Cronbach's $\alpha$ ranged from .88 to .93 for PA and from .60 to .71 for NA in the present study.

Brunel Mood Scale. In addition to the PANAS, the Brunel Mood Scale (BMS; Terry, Lane, \& Fogarty, 2003; Terry, Lane, Lane, \& Keohane, 1999; Appendix Q) was also administered before the initial baseline and after the two presentations of the IAPS image sets. The 24-item BMS consists of a list of adjectives in which the participants rated their mood on a 5-point Likert-type scale, ranging from "not at all" to "extremely." There are six dimensions of the BMS: Anger (angry, annoyed, bad-tempered, and bitter), Confusion (confused, mixed-up, muddled, and uncertain), Depression (depressed, downhearted, miserable, and unhappy), Fatigue (exhausted, sleepy, tired, and worn-out), Tension (anxious, nervous, panicky, and worried), and Vigor (active, alert, energetic, and lively). Each participant had six scores by summing the items in each category. The BMS is a valid and reliable scale (Terry et al., 1999). The Cronbach's $\alpha$ for the BMS ranged from .81 to .83 in the present study.

Self-worth questionnaire. Self-affirmation can restore or sustain feelings of self-worth (Steele, 1988). A revised version of the self-worth questionnaire (SWQ; Critcher \& Dunning, 2015; Appendix R) was included to confirm the findings of previous research and to serve as a self-affirmation manipulation check. The SWQ consists of 14 items that aim to measure participants' sense of self-worth on a 9-point Likert-type scale, ranging from "not at all" to "extremely". Examples of the statements are "I currently feel confident" and "overall, I feel positively toward myself right now." The revised version used in this study included only the seven positive items, as the manipulations of the experiment should not lead to negative feelings of self-worth. Participants were asked to complete the SWQ three times throughout the experiment: before the initial baseline and after the two writing exercises (control and self- 
affirmation). The SWQ showed high Cronbach's $\alpha$ coefficients ranging from .83 to .88 in the present study.

Post-writing exercise questionnaires. Participants were asked to complete a 4-item postwriting exercise questionnaire (Appendix S) after the control and self-affirmation writing tasks. Serving as another manipulation check, the four questions include: "in general, how do you feel about yourself at this moment," "how personally meaningful did you find this writing exercise," "how much would you agree that this writing exercise made you more aware of what you value," and "how much would you agree that this writing exercise made you think about how your value is personally important to you." Participants answered the first item using a 9-point Likert-type scale ranging from "extremely negative" to "extremely positive." A 7- point Likert-type scale was used for the remaining three questions: ranging from "not at all" to "very much" for the second item, and from "strongly disagree" to "strong agree" for the last two items. These manipulation check items were based on the questions used in the previous studies (Cohen et al., 2000; Ruiter, 2011; Siegel, Scillitoe, \& Parks-Yancy, 2005). The Cronbach's $\alpha$ for the control and self-affirmation writing exercises in the present study were .81 and .80 respectively.

IAPS task related perceived stress questionnaire. Participants' perceived stress levels after the IAPS images presentations were examined using a 3-item self-report questionnaire (Appendix T). The questions include "how stressful have you found the image presentation to be," "was the image presentation cognitively demanding," and "how would you rate your stress level now." Participants were asked to answer each question on a 5-point Likert-type scale, ranging from "not at all" to "extremely." The perceived stress scores were computed by summing the three items. The questionnaire were administered after both IAPS image presentations. This questionnaire is a revised version of the one used in previous research, and it 
showed a good reliability (Chen, 2012). In the present study, the Cronbach's $\alpha$ for this perceived stress questionnaires ranged from .79 to .83 .

\section{Evaluation of the Writing Exercises}

In addition to the manipulation check questions asked in SWQ and post-writing exercise questionnaire, participants' writings (both control and self-affirmation essays) were evaluated independently by four judges (two males and two females) after data collection. Judges were asked to rate the writings on four separate 7-point Likert-type scales (ranging from "not at all" to "very") based on the level of self-affirmation, how positive the participants felt about themselves, to what extent they followed the instruction of the writing exercise, and the importance of the value written in the writing exercise (Appendix U). These items are derived from the study of Harris and Napper (2005). The inter-rater consistency among the four judges was acceptable with correlations ranging from .55 to .84 for the control writing exercise and from .50 to .89 for the self-affirmation writing exercise.

\section{Procedure}

The present study consisted of two portions: (a) online questionnaires and (b) in-person experimental session. In the first part, prospective participants were asked to complete online surveys, including the cardiovascular health history questionnaire, RSES, CSES, LOT-R, HSM, BRS, DASS-21, perspective and affirmational thinking questionnaire, and a demographic questionnaire. Those who did not have severe cardiovascular or respiratory problems were invited back to the second part of the study, in which each participants completed the in-person experiment individually. After obtaining participants' informed consent upon their arrival, the PANAS, BMS, and SWQ were given to the participants to complete. The initial 5-min cardiovascular baseline measures were then collected. 
As this study used a within-subject design, all participants completed both the control and self-affirmation conditions. Each condition consisted of a 5-min writing exercise (jelly bean or self-affirmation), a set of IAPS images, and a 5-min recovery period. Upon the completion of the writing exercise, the experimenter administered the PANAS, SWQ, and post-writing exercise questionnaire, which were followed by the presentation of one set of IAPS images to induce positive and negative affect. Two practice trials with neutral images took place prior to the first image set. Immediately after the 14-min IAPS affect manipulation, a 5-min recovery period took place, in which the participants were asked to complete the PANAS, BMS, and perceived stress questionnaire.

The next condition, including the writing exercise, second set of IAPS images, second recovery period, and another sets of questionnaires, was presented after the first recovery period. The order of the condition (control and self-affirmation); participants who went through control condition first would complete the self-affirmation in the second part, and vice versa. The presentations of the IAPS image sets were also counterbalanced, yielding a total of four combinations (condition $\mathrm{x}$ image set). The second 5-min resting baseline was recorded after the second recovery. Participants were then debriefed at the end of the experiment. Figure 1 shows the procedural timeline for the in-person experiment.

Control or Self-Affirmation Control or Self-Affirmation

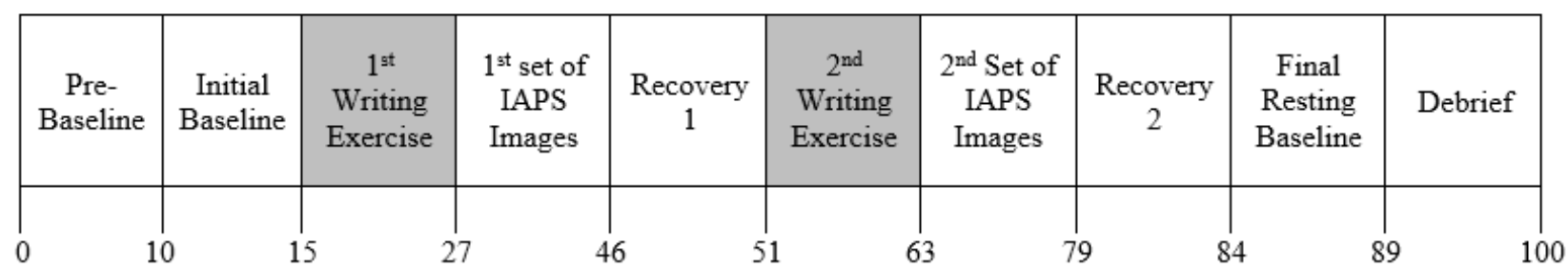

Figure 1. Procedural timeline for the experiment. The numbers at the bottom of the figure represent the duration in min. The amount of time the experimenter took to deliver the instructions are accounted for in this timeline. The order of the writing exercise was counterbalanced (control and self-affirmation) as well as the order of the International Affective Picture System (IAPS) image sets. 


\section{Results}

\section{Data Analyses}

Multiple repeated-measures analyses of variance (ANOVAs) and analyses of covariance (ANCOVAs) with Greenhouse-Geisser corrections were conducted for hypotheses testing and additional exploratory analyses. The Benjamini-Hochberg (B-H) Procedure (Benjamini \& Hochberg, 1995) was used to correct for the multiple comparisons in all the data analyses. The false discovery rate (FDR) used to compute the B-H critical values, $(i / m) Q$, was 0.05 . The variables tested in the analyses were ordered based on the $p$ values (from the smallest to the largest), and a B-H critical value was computed for each comparison based on the order or rank and on the total number of comparisons. After the application of the $\mathrm{B}-\mathrm{H}$ procedure, for the manipulation checks, the range of the $p$ values for the significant results was $7.17 \times 10^{-84}$ to 2.58 $\mathrm{x} 10^{-4}$. For the hypotheses testing, this range was $5.30 \times 10^{-5}$ to .006 ; the next variable with a significant $p$ value $(p=.021)$ and the following variables were not considered as statistically significant. The significant ranges for the additional exploratory repeated-measures analyses as well as correlations and regressions were $1.67 \times 10^{-4}$ to 0.003 and $6.24 \times 10^{-12}$ to 0.009 respectively.

\section{Manipulation Checks}

Affect manipulation check. To ensure the sets of IAPS images induce emotions successfully, participants' valence scores from SAM were analyzed and compared among pictures using a repeated-measures ANOVA with Greenhouse-Geisser correction, $F(1.55$, $191.86)=1544.43, p<.001, \eta_{p}^{2}=.93$. Higher negative valence ratings were seen for negative images compared to the positive images, $F(1,124)=2031.72, p<.001, \eta_{p}^{2}=.94$, and to the neutral images, $F(1,124)=1213.42, p<.001, \eta_{p}^{2}=.91$. Positive images also showed higher 
positive valence scores compared to the neutral images, $F(1,124)=804.92, p<.001, \eta_{p}^{2}=.87$. Therefore, emotion induction via IAPS image presentations was effective. Descriptive statistics of the valence scores are shown in Table 2.

Table 2

Descriptive Statistics of Valence Scores for the Images

95\% CI for Mean

\begin{tabular}{lccccc} 
& $M$ & $S D$ & $S E$ & Lower & Upper \\
\hline Positive Images & 2.21 & 0.83 & 0.08 & 2.06 & 2.36 \\
\hline Neutral Images & 4.46 & 0.89 & 0.08 & 4.31 & 4.62 \\
\hline Negative Images & 8.05 & 0.82 & 0.07 & 7.90 & 8.19
\end{tabular}

Note. Higher valence scores represent more negative affect. $M=$ mean; $S D=$ standard deviation; $S E=$ standard error $; \mathrm{CI}=$ confidence interval. The $p$ values for all comparisons were smaller than $4.60 \times 10^{-56}$.

Self-affirmation manipulation check. Successful self-affirmation manipulation was confirmed by the greater feelings of self-worth (measured using the SWQ) after controlling for the baseline SWQ scores, $F(1,123)=14.16, p<.001, \eta_{p}^{2}=.10$, and by the higher perceived meaningfulness of the writing exercise (measured by the post-writing exercise questionnaire), $F(1,124)=657.36, p<.001, \eta_{p}^{2}=.74$. Furthermore, judges had higher ratings for the writings during the self-affirmation condition than during the control condition. Through evaluations of the self-affirmation writings, participants were shown to have higher levels of self-affirmation (question 1 in Appendix U), $F(1,124)=1398.43, p<.001, \eta_{p}^{2}=.92$, greater positive scores (question 2 in Appendix U), $F(1,124)=2098.78, p<.001, \eta_{p}^{2}=.94$, and greater perceived importance (question 4 in Appendix U), $F(1,124)=2483.06, p<.001, \eta_{p}^{2}=.95$, compared to the control condition. Descriptive statistics of these manipulation check variables are reported in Table 3. 
Table 3

Descriptive Statistics for the Self-Affirmation Manipulation Check

\begin{tabular}{|c|c|c|c|c|c|}
\hline & \multirow[b]{2}{*}{$M$} & \multirow[b]{2}{*}{$S D$} & \multirow[b]{2}{*}{$S E$} & \multicolumn{2}{|c|}{$95 \%$ CI for Mean } \\
\hline & & & & Lower & Upper \\
\hline \multicolumn{6}{|l|}{ Self-Reported Responses } \\
\hline Self-Worth $^{*}$ & 2.42 & 7.12 & 0.64 & 1.15 & 3.70 \\
\hline Control & 44.82 & 11.66 & 0.56 & 43.71 & 45.92 \\
\hline Self-Affirmation & 47.24 & 11.29 & 0.62 & 46.01 & 48.47 \\
\hline Meaningfulness $^{* *}$ & 8.47 & 5.01 & 0.45 & 7.59 & 9.36 \\
\hline Control & 14.95 & 5.18 & 0.46 & 14.04 & 15.87 \\
\hline Self-Affirmation & 23.42 & 4.58 & 0.41 & 22.61 & 24.24 \\
\hline \multicolumn{6}{|l|}{ Evaluations of the Judges } \\
\hline Level of Self-Affirmation $^{* * *}$ & 11.42 & 3.42 & 0.31 & 10.82 & 12.03 \\
\hline Control & 9.46 & 1.53 & 0.14 & 9.19 & 9.73 \\
\hline Self-Affirmation & 20.89 & 3.23 & 0.29 & 20.31 & 21.45 \\
\hline Positive Scores ${ }^{* * *}$ & 12.80 & 3.12 & 0.28 & 12.25 & 13.35 \\
\hline Control & 9.74 & 0.12 & 0.12 & 9.51 & 9.97 \\
\hline Self-Affirmation & 22.54 & 0.31 & 0.31 & 21.93 & 23.16 \\
\hline Perceived Importance ${ }^{* * *}$ & 12.51 & 2.81 & 0.25 & 12.02 & 13.01 \\
\hline Control & 10.17 & 1.51 & 0.14 & 9.90 & 10.44 \\
\hline Self-Affirmation & 22.68 & 2.88 & 0.26 & 22.17 & 23.19 \\
\hline
\end{tabular}

Note. Within-individual differences between the two conditions are reported in the same rows as the variable names. $M=$ mean; $S D=$ standard deviation; $S E=$ standard error; $\mathrm{CI}=$ confidence interval.

$* p<.001 . * * p<2.50 \times 10^{-38}$.*** $p<2.23 \times 10^{-69}$.

\section{Hypotheses Testing}

Multiple repeated-measures ANCOVAs with Greenhouse-Geisser corrections were conducted to test the hypotheses, which state that compared to the control condition (a) participants would show lower cardiovascular arousal (lower average HR, lower maximum HR, and greater RSA) to negative images in the self-affirmation condition, (b) recovery rates of HR would be shorter after presentations of negative images after self-affirmation, and (c) selfaffirmation would produce lower ratings of negative affect during negative image presentations and after IAPS image presentations. The order of the conditions was examined along with the analyses. However, no statistically significant order effects or interaction effects were found (all 
$p$ s > .102); therefore, all participants' data were assessed together without splitting the data by the order.

Due to the large fluctuations in second to second HR calculations, recovery rates of HR after the images could not be reliably assessed. Therefore, the second hypothesis could not be tested using the collected data. Nevertheless, the other cardiovascular measures, including the average $\mathrm{HR}$, maximum HR, and RSA in response to the negative images, could still be examined. For these measures, the hypotheses were partially supported. No statistically significant results were found for the average $\mathrm{HR}$ in response to the negative images, $F(1,123)=$ $1.84, p=.178$, and for the NA after IAPS image presentations, $F(1,123)=0.02, p=.883$. However, results showed that after the self-affirmation writing exercise, participants had lower maximum HR, $F(1,118)=7.82, p=.006, \eta_{p}^{2}=.06$, showed higher RSA levels to the negative images, $F(1,118)=9.28, p=.003, \eta_{p}^{2}=.07$, and reported lower ratings of negative affect (negative valence scores) to the negative images, $F(1,124)=17.52, p<.001, \eta_{p}^{2}=.12$, compared to the control condition. The descriptive statistics are shown in Table 4. The findings suggestion that self-affirmation may be helpful in buffering against negative emotion.

Table 4 Descriptive Statistics for Hypotheses Testing

\begin{tabular}{lrrrrr}
\hline & & & \multicolumn{3}{c}{$95 \%$ CI for Mean } \\
& $M$ & $S D$ & $S E$ & Lower & Upper \\
\hline During IAPS Image Presentations & & & & & \\
\hline Average HR & 1.24 & 10.25 & 0.92 & -0.57 & 3.06 \\
$\quad$ Control & 81.70 & 15.26 & 1.19 & 79.36 & 84.05 \\
$\quad$ Self-Affirmation & 80.46 & 14.15 & 1.02 & 78.43 & 82.48 \\
\hline Maximum HR & 3.79 & 14.91 & 1.36 & 1.09 & 6.48 \\
Control & 91.73 & 18.92 & 1.63 & 88.49 & 94.96 \\
$\quad$ Self-Affirmation & 87.94 & 87.94 & 1.05 & 85.86 & 90.03 \\
\hline RSA $^{* *}$ & 0.02 & 0.07 & 0.01 & 0.01 & 0.03 \\
Control & 0.10 & 0.08 & 0.01 & 0.08 & 0.11 \\
$\quad$ Self-Affirmation & 0.11 & 0.12 & 0.01 & 0.10 & 0.13 \\
\hline
\end{tabular}




\begin{tabular}{lrrrrr}
\hline Valence for Negative Images ${ }^{* * *}$ & 0.20 & 0.53 & 0.05 & 0.10 & 0.29 \\
Control & 8.15 & 0.85 & 0.08 & 8.00 & 8.30 \\
Self-Affirmation & 7.95 & 0.88 & 0.08 & 7.79 & 8.10 \\
\hline After IAPS Image Presentations & & & & & \\
\hline NA from PANAS & 0.03 & 2.54 & 0.23 & -0.42 & 0.49 \\
$\quad$ Control & 12.35 & 2.93 & 0.24 & 11.88 & 12.81 \\
Self-Affirmation & 12.31 & 2.81 & 0.22 & 11.88 & 12.75 \\
\hline
\end{tabular}

Note. Average heart rate (HR), maximum heart rate (HR), respiratory sinus arrhythmia (RSA), and valence scores were participants' responses to the negative images. Within-individual differences between the two conditions are reported in the same rows as the variable names. $M=$ mean; $S D=$ standard deviation; $S E=$ standard error; $\mathrm{CI}=$ confidence interval; PANAS = Positive and Negative Affect Schedules; IAPS = International Affective Picture System. $* p<.007 . * * p<.003 . * * * p<5.30 \times 10^{-5}$.

\section{Additional Analyses}

Cardiovascular responses. Repeated-measures ANCOVAs were conducted using baseline cardiovascular responses as covariates. No statistically significant differences between the control and the self-affirmation conditions were found in blood pressure after the writing exercises [SBP: $F(1,122)=0.05, p=.822$; DBP: $F(1,122)=2.05, p=.155]$ and after the IAPS image presentations [SBP: $F(1,122)=4.92, p=.028$, which was not statistically significant after the B-H correction; DBP: $F(1,123)=0.40, p=.529$ ]. Participants' average HR and maximum HR in response to the positive and neutral images during the IAPS image presentations did not differ statistically after the $\mathrm{B}-\mathrm{H}$ correction [average $\mathrm{HR}_{\text {Positive: }} F(1,123)=2.17, p=.143$; average $\mathrm{HR}_{\text {Neutral: }} F(1,123)=2.77, p=.098$; maximum HR $\mathrm{Hositive}_{\mathrm{f}} F(1,117)=2.88, p=.092 ;$ maximum $\mathrm{HR}_{\text {Neutral }}: F(1,116)=7.44, p=.007$, which was not statistically significant after the $\mathrm{B}-\mathrm{H}$ correction]. The difference between the control and self-affirmation conditions in participants' RSA in response to neutral images was also not significant, $F(1,120)=0.30, p=.584$. Importantly, results showed that compared to the control condition, after the self-affirmation exercise, participants showed higher RSA levels to the positive images, $F(1,119)=11.45, p$ $=.001, \eta_{p}^{2}=.09$. 
In addition to assessing participants' responses to the images, cardiovascular activity during the control and self-affirmation writing exercise was also examined. Participants showed greater HF-HRV, $F(1,123)=35.35, p<.001, \eta_{p}^{2}=.22$, and higher RSA, $F(1,119)=14.47, p$ $<.001, \eta_{p}^{2}=.11$, during self-affirmation compared to the control condition, suggesting that selfaffirmation led to more parasympathetic activity. Table 5 shows the descriptive statistics for the variables in the above analyses.

Table 5

Descriptive Statistics for Cardiovascular Responses in Additional Analyses

\begin{tabular}{lrrrrr}
\hline & & & & \multicolumn{2}{c}{$95 \%$ CI for Mean } \\
& $M$ & $S D$ & $S E$ & Lower & Upper \\
\hline During Writing Exercises & & & & & \\
\hline HF-HRV $^{* * *}$ & 6.58 & 12.33 & 1.11 & 4.39 & 8.77 \\
Control & 33.06 & 14.81 & 1.21 & 30.68 & 35.45 \\
Self-Affirmation & 39.64 & 16.74 & 1.38 & 36.92 & 42.36 \\
\hline RSA $^{* *}$ & 0.03 & 0.10 & 0.01 & 0.02 & 0.05 \\
Control & 0.10 & 0.09 & 0.01 & 0.09 & 0.11 \\
Self-Affirmation & 0.13 & 0.14 & 0.01 & 0.11 & 0.15 \\
\hline After Writing Exercises & & & & & \\
\hline SBP & 0.19 & 8.58 & 0.77 & -1.32 & 1.71 \\
Control & 119.23 & 12.27 & 0.79 & 117.67 & 120.80 \\
Self-Affirmation & 119.43 & 11.07 & 0.75 & 117.94 & 120.91 \\
\hline DBP & 0.98 & 7.68 & 0.69 & -0.39 & 2.34 \\
Control & 72.67 & 10.25 & 0.74 & 71.19 & 74.15 \\
Self-Affirmation & 71.69 & 8.30 & 0.56 & 70.58 & 72.81 \\
\hline During IAPS Image Presentations & & & & & \\
\hline Average HR to Positive Images & 2.34 & 17.69 & 1.59 & -0.80 & 5.48 \\
Control & 84.15 & 20.82 & 1.74 & 80.71 & 87.59 \\
Self-Affirmation & 81.81 & 14.34 & 1.05 & 79.74 & 83.88 \\
\hline Average HR to Neutral Images & 1.37 & 9.24 & 0.83 & -0.26 & 3.01 \\
Control & 82.92 & 15.24 & 1.19 & 80.56 & 85.28 \\
Self-Affirmation & 81.54 & 13.85 & 1.00 & 79.76 & 83.52 \\
\hline Maximum HR to Positive Images & 3.45 & 22.04 & 2.03 & -0.57 & 7.47 \\
Control & 94.55 & 22.69 & 1.99 & 90.61 & 98.48 \\
Self-Affirmation & 91.10 & 18.67 & 1.60 & 87.92 & 94.27 \\
\hline Maximum HR to Neutral Images & 3.51 & 14.08 & 1.30 & 0.94 & 6.01 \\
Control & 92.40 & 18.62 & 1.60 & 89.24 & 95.57 \\
Self-Affirmation & 88.90 & 13.83 & 1.04 & 86.84 & 90.96 \\
\hline$\quad$ & & & &
\end{tabular}




\begin{tabular}{|c|c|c|c|c|c|}
\hline RSA to Positive Images" & 0.22 & 0.21 & 0.01 & 0.20 & 0.25 \\
\hline Control & 0.10 & 0.09 & 0.01 & 0.08 & 0.11 \\
\hline Self-Affirmation & 0.13 & 0.14 & 0.01 & 0.11 & 0.15 \\
\hline RSA to Neutral Images & 0.26 & 0.26 & 0.01 & 0.23 & 0.29 \\
\hline Control & 0.12 & 0.14 & 0.01 & 0.11 & 0.15 \\
\hline Self-Affirmation & 0.13 & 0.14 & 0.01 & 0.11 & 0.15 \\
\hline \multicolumn{6}{|c|}{ After IAPS Image Presentations } \\
\hline SBP & 1.60 & 7.98 & 0.72 & 0.17 & 3.02 \\
\hline Control & 119.41 & 12.18 & 0.73 & 117.97 & 120.86 \\
\hline Self-Affirmation & 117.82 & 11.93 & 0.70 & 116.42 & 119.21 \\
\hline DBP & 0.46 & 8.06 & 0.72 & -0.98 & 1.89 \\
\hline Control & 73.79 & 9.91 & 0.65 & 72.51 & 75.07 \\
\hline Self-Affirmation & 73.34 & 9.50 & 0.57 & 72.21 & 74.46 \\
\hline
\end{tabular}

Note. Within-individual differences between the two conditions are reported in the same rows as the variable names. $M=$ mean; $S D=$ standard deviation; $S E=$ standard error; $\mathrm{CI}=$ confidence interval; HF-HRV = high-frequency heart rate variability; RSA = respiratory sinus arrhythmia; $\mathrm{SBP}=$ systolic blood pressure $; \mathrm{DBP}=$ diastolic blood pressure; IAPS = International Affective Picture System; HR = heart rate.

$* p<.001 . * * p<.0003$. *** $p<2.66 \times 10^{-8}$.

Positive and negative affect. Repeated-measures ANCOVAs were conducted using the baseline NA scores from PANAS as the covariate. Results with Greenhouse-Geisser correction showed no statistical significance for the negative affect after the writing exercises, $F(1,122)=$ $0.21, p=.647$, and after the IAPS image presentations, $F(1,123)=0.02, p=.883$. Participants' valence scores for the IAPS positive and neutral images were also not significant [Positive: $F(1$, $124)=1.68, p=.198 ;$ Neutral: $F(1,124)=7.17, p=.008$, which was not statistically significant after the B-H correction]. Furthermore, results for the six constructs of the BMS after the IAPS presentations, as well as the IAPS task related perceived stress scores were not statistically significant [Anger: $F(1,124)=3.64, p=.059$; Confusion: $F(1,124)=0.66, p=.420$; Depression: $F(1,124)=2.95, p=.089$; Fatigue: $F(1,124)=0.003, p=.957$; Tension: $F(1,124)$ $=0.01, p=.931$; Vigor: $F(1,124)=0.002, p=.965$; IAPS task related stress: $F(1,124)=0.11, p$ $=.742]$. Table 6 shows the descriptive statistics for the above analyses. 
Table 6

Descriptive Statistics for Positive and Negative Affect in Additional Analyses

\begin{tabular}{|c|c|c|c|c|c|}
\hline & \multirow[b]{2}{*}{$M$} & \multirow[b]{2}{*}{$S D$} & \multirow[b]{2}{*}{$S E$} & \multicolumn{2}{|c|}{$95 \%$ CI for Mean } \\
\hline & & & & Lower & Upper \\
\hline \multicolumn{6}{|l|}{ After Writing Exercises } \\
\hline NA from PANAS & 0.08 & 2.02 & 0.18 & -0.28 & 0.44 \\
\hline Control & 11.48 & 1.86 & 0.14 & 11.21 & 11.76 \\
\hline Self-Affirmation & 11.56 & 2.20 & 0.16 & 11.25 & 11.88 \\
\hline \multicolumn{6}{|l|}{ During IAPS Image Presentations } \\
\hline Valence for Positive Images & 0.08 & 0.71 & 0.06 & -0.04 & 0.21 \\
\hline Control & 2.25 & 0.90 & 0.08 & 2.09 & 2.41 \\
\hline Self-Affirmation & 2.17 & 0.92 & 0.08 & 2.01 & 2.33 \\
\hline Valence for Neutral Images & 0.16 & 0.67 & 0.06 & 0.04 & 0.28 \\
\hline Control & 4.54 & 0.89 & 0.08 & 4.39 & 4.70 \\
\hline Self-Affirmation & 4.38 & 1.00 & 0.09 & 4.21 & 4.56 \\
\hline \multicolumn{6}{|l|}{ After IAPS Image Presentations } \\
\hline Anger & 0.14 & 0.80 & 0.07 & -0.01 & 0.28 \\
\hline Control & 4.54 & 1.18 & 0.10 & 4.33 & 4.73 \\
\hline Self-Affirmation & 4.40 & 0.92 & 0.07 & 4.26 & 4.54 \\
\hline Confusion & 0.10 & 1.44 & 0.13 & -0.15 & 0.36 \\
\hline Control & 5.28 & 1.98 & 0.15 & 4.98 & 5.58 \\
\hline Self-Affirmation & 5.38 & 2.12 & 0.16 & 5.06 & 5.71 \\
\hline Depression & 0.13 & 0.87 & 0.08 & -0.02 & 0.29 \\
\hline Control & 4.88 & 1.62 & 0.12 & 4.64 & 5.11 \\
\hline Self-Affirmation & 5.01 & 1.96 & 0.14 & 4.72 & 5.29 \\
\hline Fatigue & 0.01 & 2.19 & 0.19 & -0.37 & 0.39 \\
\hline Control & 9.96 & 3.64 & 0.23 & 9.50 & 10.42 \\
\hline Self-Affirmation & 9.95 & 3.95 & 0.24 & 9.48 & 10.41 \\
\hline Tension & 0.02 & 2.05 & 0.18 & -0.35 & 0.38 \\
\hline Control & 5.48 & 2.10 & 0.15 & 5.19 & 5.77 \\
\hline Self-Affirmation & 5.50 & 2.44 & 0.17 & 5.17 & 5.82 \\
\hline IAPS Related Perceived Stress & 0.01 & 2.03 & 0.18 & -0.35 & 0.37 \\
\hline Control & 6.00 & 2.54 & 0.23 & 5.55 & 6.45 \\
\hline Self-Affirmation & 5.95 & 2.40 & 0.21 & 5.53 & 6.38 \\
\hline
\end{tabular}

Note. Within-individual differences between the two conditions are reported in the same rows as the variable names. Results of PA and vigor are discussed in the next subsection. $M=$ mean; $S D$ $=$ standard deviation; $S E=$ standard error; $\mathrm{CI}=$ confidence interval; $\mathrm{PA}=$ positive affect; $\mathrm{NA}=$ negative affect; PANAS = Positive and Negative Affect Schedules; IAPS = International Affective Picture System. 
Interactions with order. Although the order of the IAPS image presentations did not reveal significant main or interaction effects, the order of the condition (control condition first or self-affirmation condition first) significantly interacted with condition for participants' average HR during the writing exercises, $F(1,119)=85.45, p<.001, \eta_{p}^{2}=.42$, PA after the writing exercises, $F(1,121)=74.01, p<.001, \eta_{p}^{2}=.38$, PA after the IAPS image presentations, $F(1$, $122)=70.71, p<.001, \eta_{p}^{2}=.37$, and vigor after the IAPS image presentations $F(1,122)=$ 22.31, $p<.001, \eta_{p}^{2}=.16$. Similar patterns were shown for these four variables (shown in Figures 2-5 and Table 7). Regardless of which condition the participants went through first (control or self-affirmation), decreases in HR during writing exercises, PA after writing exercises, and PA and vigor after IAPS image presentations were shown from the first condition to the second condition (control to self-affirmation or affirmation to control). It is possible that participants' PA and vigor levels dropped due to the various tasks they were asked to complete in the $1 \mathrm{hr}$ and 40 min experiment. Furthermore, the decrease in HR may be associated with the increased familiarity with the task and experiment, showing less physiological arousal during the second writing exercise compared to the first.
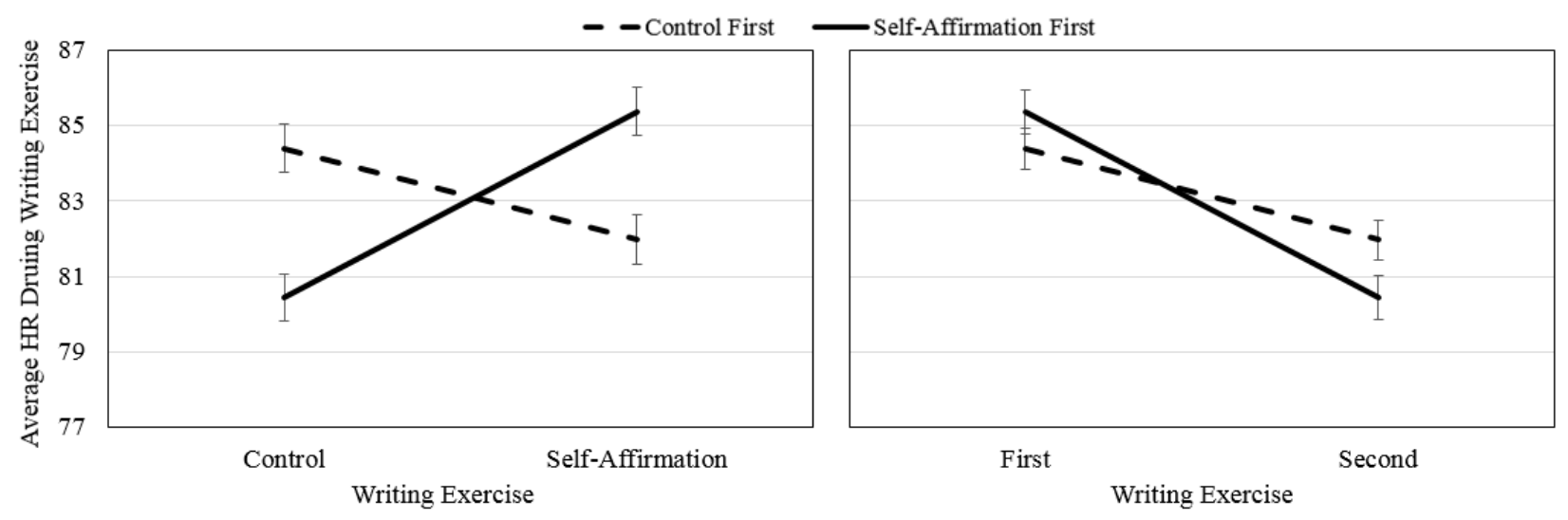

Figure 2. Interaction effect for average heart rate (HR) during writing exercises. The left plot reflects the interaction between the order and condition, whereas the right plot is based on the timeline of the experiment showing the drop in HR from the first to second writing exercise. 

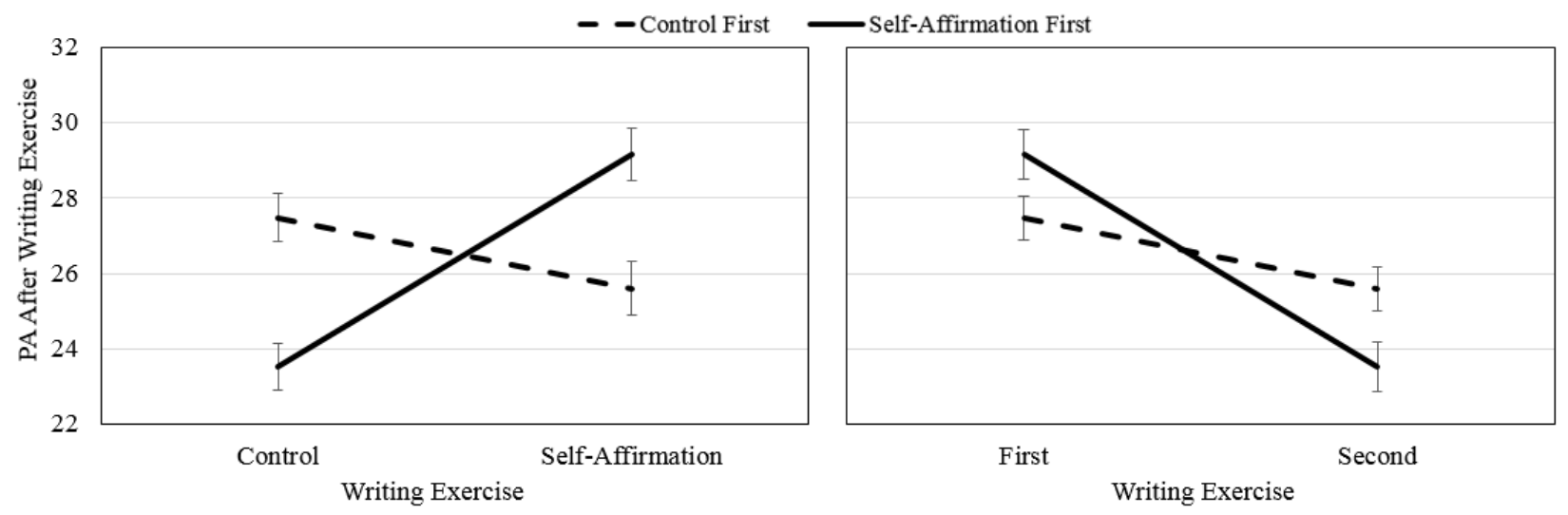

Figure 3. Interaction effect for positive affect (PA) after writing exercises. The left plot reflects the interaction between the order and condition, whereas the right plot is based on the timeline of the experiment showing the drop in PA from the first to second writing exercise.
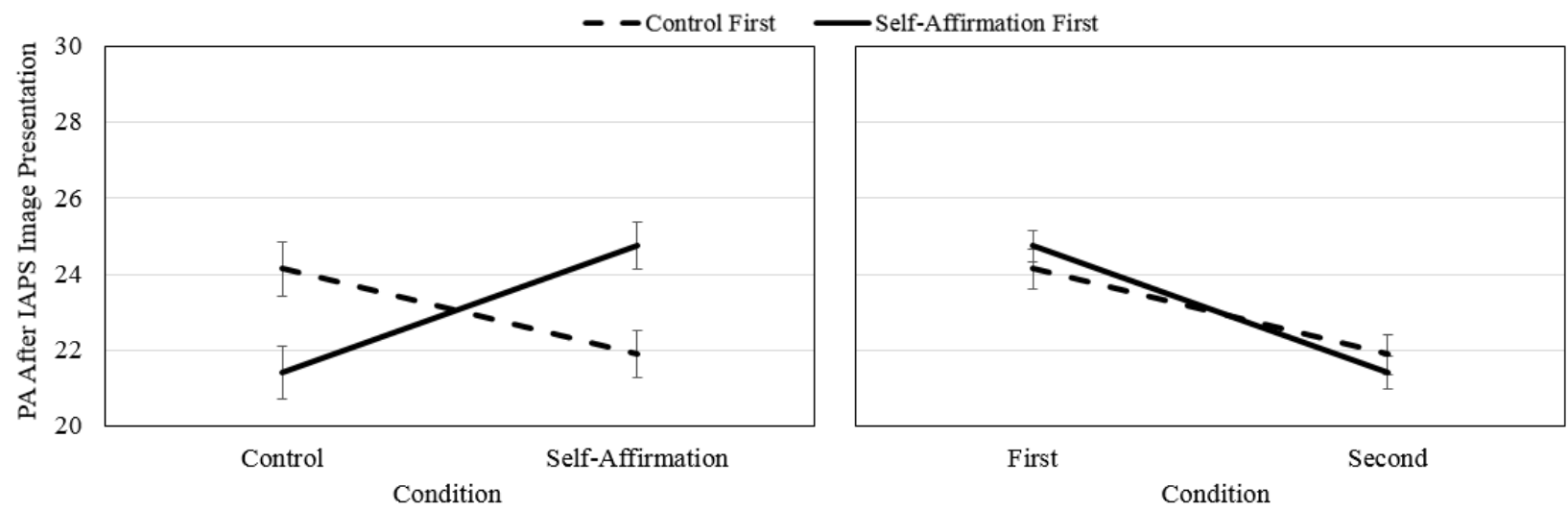

Figure 4. Interaction effect for positive affect (PA) after image presentations. The left plot reflects the interaction between the order and condition, whereas the right plot is based on the timeline of the experiment showing the drop in PA from the first to second condition.
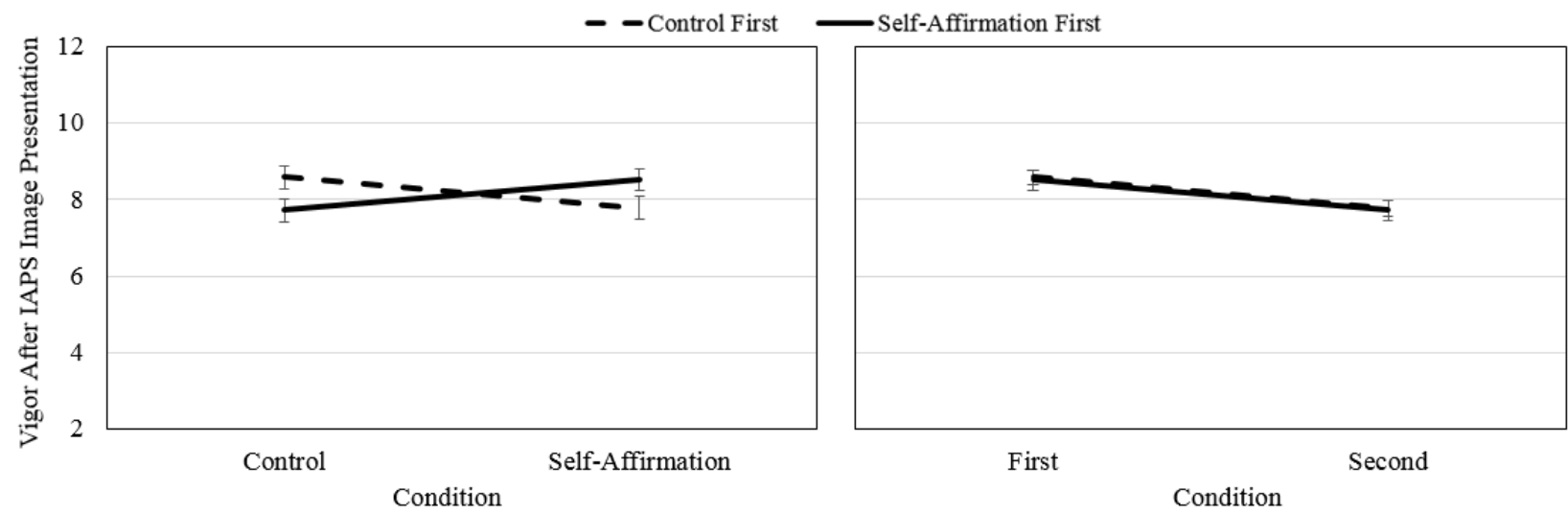

Figure 5. Interaction effect for vigor after image presentations. The left plot reflects the interaction between the order and condition, whereas the right plot is based on the timeline of the experiment showing the drop in vigor scores from the first to second condition. 
Table 7

Descriptive Statistics for Interactions with Order of the Conditions

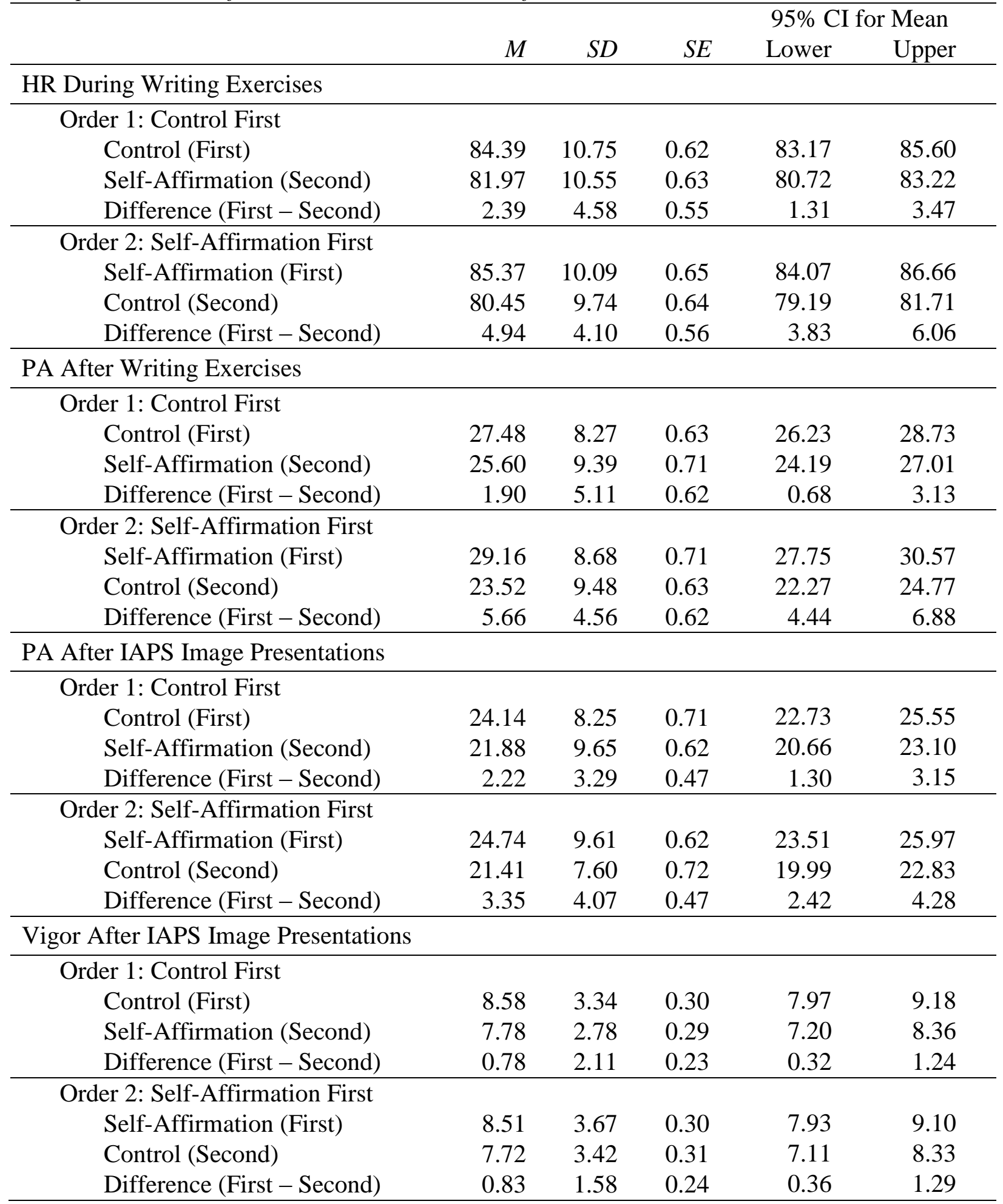

Note. $M=$ mean; $S D=$ standard deviation; $S E=$ standard error; $\mathrm{CI}=$ confidence interval;

$\mathrm{HR}=$ heart rate; $\mathrm{PA}=$ positive affect; PANAS = Positive and Negative Affect Schedules;

IAPS = International Affective Picture System . 
One-way between-subjects ANCOVAs controlling for baseline measures were conducted to test the differences between the two orders in the first and second writing exercises as well as in the first and second IAPS image presentations. None of the results were statistically significant. Participants' HR, $F(1,122)=0.35, p=.556$, and PA, $F(1,121)=4.39, p=.038$ (not statistically significant after B-H correction), did not significantly differ for the first writing exercise (between control and self-affirmation conditions); the differences in the second writing exercise were also not significant [HR: $F(1,122)=4.64, p=.033$, which was not statistically significant after the B-H correction; PA: $F(1,122)=3.17, p=.078]$. The PA and vigor scores between the two orders (control first or self-affirmation first) after the first and second IAPS image presentations were not significantly different either [PAFirstIAPs: $F(1,122)=0.44, p=.508$; PASecondIAPS: $F(1,122)=0.28, p=.601$; Vigor FirstIAPs: $F(1,122)=0.01, p=.935$; VigorsecondIAPs: $F(1,122)=0.05, p=.830]$.

Simple effects and the amplitudes of the difference (differences between first and second writing exercise as well as between first and second IAPS image presentations) were also examined. Participants' HR dropped from the first to the second writing exercise regardless of the order. However, those who went through self-affirmation condition first had a larger decrease in $\mathrm{HR}$ (HR in the first writing exercise minus the HR in the second writing exercise), $F(1,119)=$ $10.60, p=.001, \eta_{p}^{2}=.08$. PA after the writing exercises showed the same pattern; participants who wrote about their value first (self-affirmation condition) showed a greater drop in PA compared to the other group, $F(1,121)=18.41, p<.001, \eta_{p}^{2}=.13$. The amplitudes of the difference were not significant for PA, $F(1,122)=2.88, p=.092$, and vigor, $F(1,122)=20.02, p$ $=.881$, after the IAPS image presentations. These results may have suggested that for participants who went from the more meaningful writing exercise (self-affirmation) to the less 
meaning one (control), their HR and PA dropped more during and immediately after the writing exercises.

Regression analyses. Several multiple regression analyses were conducted using selfresources (i.e., personal self-esteem, collective self-esteem, dispositional optimism, selfenhancement, resilience, psychological discomfort, and perspective/affirmation thinking) as predictors of cardiovascular and self-report measures (descriptive statistics for the self-resources variables are shown in Table 8). Self-resources did not significantly predict any of the physiological measures. However, after B-H correction, statistically significant results were found for self-worth levels, perceived meaningfulness of the writing exercises, NA after the writing exercises and IAPS image presentations, valence scores in response to negative images, as well as confusion, tension, depression, fatigue, and perceived stress scores after the IAPS image presentations in in both the control condition and the self-affirmation condition. Statistical findings are reported in Table 9.

Table 8

Descriptive Statistics for Self-Resources

\begin{tabular}{lccc}
\hline Variable & $M$ & $S D$ & $S E$ \\
\hline Self-Esteem & 30.70 & 4.95 & 0.44 \\
\hline Collective Self-Esteem & & & \\
$\quad$ Membership & 22.06 & 4.41 & 0.39 \\
$\quad$ Private & 22.11 & 4.60 & 0.41 \\
$\quad$ Public & 21.42 & 4.06 & 0.36 \\
$\quad$ Identity & 19.10 & 4.30 & 0.38 \\
\hline Optimism & 10.27 & 3.97 & 0.35 \\
\hline Self-Enhancement & 98.01 & 9.60 & 0.86 \\
\hline Resilience & 3.28 & 0.79 & 0.07 \\
\hline Perspective Thinking & 35.17 & 7.52 & 0.67 \\
\hline Affirmational Thinking & 32.35 & 7.33 & 0.66 \\
\hline Psychological Distress & & & \\
$\quad$ Anxiety & 6.61 & 7.13 & 0.64 \\
$\quad$ Depression & 5.95 & 6.48 & 0.58 \\
$\quad$ Stress & 11.68 & 8.55 & 0.77 \\
\hline
\end{tabular}

Note. $N=125 . M=$ mean; $S D=$ standard deviation; $S E=$ standard error. 
Table 9

Results of Multiple Regression Analyses Using Self-Resources as Predictors

\begin{tabular}{|c|c|c|c|}
\hline Variable & $R$ & $R^{2}$ & $F(13,111)$ \\
\hline \multicolumn{4}{|l|}{ Control Condition } \\
\hline \multicolumn{4}{|l|}{ After Writing Exercise } \\
\hline Self-Worth ${ }^{* * *}$ & .67 & .45 & 7.05 \\
\hline Meaningfulness of Writing Exercise ${ }^{*}$ & .49 & .24 & 2.71 \\
\hline Negative Affect $^{* *}$ & .53 & .28 & 3.23 \\
\hline \multicolumn{4}{|l|}{ During IAPS Image Presentation } \\
\hline Valence for Negative Images ${ }^{* *}$ & .53 & .29 & 3.41 \\
\hline \multicolumn{4}{|l|}{ After IAPS Image Presentation } \\
\hline Negative Affect ${ }^{*}$ & .50 & .25 & 2.88 \\
\hline Confusion $^{* *}$ & .53 & .28 & 3.28 \\
\hline Tension $^{* * *}$ & .64 & .41 & 5.86 \\
\hline Depression $^{* *}$ & .51 & .26 & 3.02 \\
\hline Fatigue $^{*}$ & .46 & .21 & 2.31 \\
\hline IAPS Related Perceived Stress ${ }^{* * *}$ & .58 & .34 & 4.43 \\
\hline \multicolumn{4}{|l|}{ Self-Affirmation Condition } \\
\hline \multicolumn{4}{|l|}{ After Writing Exercise } \\
\hline Self-Worth $^{* * *}$ & .71 & .50 & 8.66 \\
\hline Meaningfulness of Writing Exercise ${ }^{* *}$ & .56 & .32 & 3.92 \\
\hline Negative Affect ${ }^{* * *}$ & .58 & .34 & 4.38 \\
\hline \multicolumn{4}{|l|}{ During IAPS Image Presentation } \\
\hline Valence for Negative Images $^{* * *}$ & .59 & .34 & 4.48 \\
\hline \multicolumn{4}{|l|}{ After IAPS Image Presentation } \\
\hline Negative Affect ${ }^{* *}$ & .57 & .32 & 4.10 \\
\hline Confusion $^{* *}$ & .53 & .28 & 3.29 \\
\hline Tension $^{* * *}$ & .64 & .41 & 5.98 \\
\hline Depression $^{* *}$ & .52 & .27 & 3.20 \\
\hline Fatigue $^{*}$ & .50 & .25 & 2.86 \\
\hline IAPS Related Perceived Stress ${ }^{* *}$ & .52 & .27 & 3.23 \\
\hline
\end{tabular}

Note. IAPS $=$ International Affective Picture System.

$* p<.01 . * * p<.001$. *** $p<6.50 \times 10^{-6}$. 
Examining the common significant predictors across theses analyses, unsurprisingly higher psychological discomfort, such as anxiety, depression, and stress, were found to be associated with lower self-worth levels, higher negative affect scores throughout the experiment, and higher perceived stress and negative mood scores after IAPS image presentations. However, a finding that is closely related to the main focus of the present study was that affirmational thinking (e.g., "I emphasize why something has made my life affirming and whole," "I affirm my worth as a person") had significant unique contributions in predicting many of these variables. Participants with more affirmational thinking perceived both writing exercises as more meaningful (control: $\beta=.30, t=2.33, p=.022$; self-affirmation: $\beta=.26, t=2.16, p=.033$ ), had higher levels of self-worth $(\beta=.23, t=2.11, p=.037)$ and lower NA scores $(\beta=-.25, t=-2.00$, $p=.048)$ after the control writing exercise, showed lower ratings of negative affect to the negative images $(\beta=.25, t=2.12, p=.036)$, and reported lower perceived stress $(\beta=.25, t=$ $2.16, p=.033)$ in response to the IAPS image presentation in the control condition. Affirmational thinking was also found to be significantly and positively correlated with selfesteem, $r(123)=.24, p=.008$, optimism, $r(123)=.32, p<.001$, and one's perceived worthiness as a group member (measured using the Membership subscale of CSES), $r(123)=.30, p=.001$.

Control condition and self-affirmation condition difference scores were used to examine whether self-resources predicted the change in physiological and self-reported responses between the control and self-affirmation conditions. However, no significant results were found. Therefore, although many self-resources were significantly associated with participants' selfreported measures separately in the control and self-affirmation conditions, they did not significantly predict the magnitudes of the differences between the two conditions. 


\section{Discussion}

The present study is one of the few studies that have examined the cardiovascular responses both during and consequent to the practice of self-affirmation as well as to the negative emotion induction. Furthermore, no studies have assessed the link between selfaffirmation and vagal tone using HF-HRV and RSA. Findings suggest that practice of selfaffirmation can increase parasympathetic cardiovascular activity and help individuals cope with negative emotion. Affirmational thinking was also positively associated with self-resources, including self-esteem, optimism, and one's perceived worthiness in a group. Not only was selfaffirmation shown to be beneficial, it may also be an attractive option for many individuals as its effects are quick and it is easy to practice with low to no cost.

The immediate effects of self-affirmation on physiological responses examined in the present study included lower maximum HR to the negative images and higher RSA to negative and positive images. Participants also reported lower negative affective response to the negative images in the self-affirmation condition compared to the control condition. Furthermore, during the self-affirmation writing exercise, participants showed higher HF-HRV and RSA. These findings suggest that self-affirmation not only lowered participants' self-reported negative affect to the negative images, it may also have increased parasympathetic activity (as indicated by lower maximum HR and higher HF-HRV and RSA) both during the self-affirmation writing exercise and during the presentations of negative images.

Past research studies have utilized tasks such as helpless training (Liu \& Steel, 1986), dissonance induction (Galinsky et al., 2000), and mortality salience and fairness manipulation (Van den Bos, 2001) to examine the effects of self-affirmation on negative affect. The present study used a direct manipulation of emotion via IAPS image presentations. Although no 
significant effects of self-affirmation on the positive affect scores were found throughout the experiment, unlike those reported in Koole et al. (1999), it was shown that self-affirmation led to less negative affect during negative emotion induction. These results of the present study are consistent with previous findings regarding self-affirmation theory, which suggests that affirming an important aspect of self may act as an indirect method of psychological adaptation (Ruiter, 2011; Sherman, 2013; Sherman \& Cohen, 2006).

Only two past studies in self-affirmation research have examined cardiovascular reactivity. The cardiovascular measures assessed in the present study included average HR, maximum HR, HF-HRV, RSA, SBP, and DBP. Consistent with the findings of Creswell et al. (2005), the SBP and DBP after the writing exercises and IAPS image presentations did not yield statistical significance; self-affirmation did not significantly impact average HR during writing exercises and in response to the negative images either. However, the present study found that participants showed lower maximum HR to the negative images after the practice of selfaffirmation. Furthermore, this study examined vagal tone using HF-HRV and RSA, neither of which were included in the past research. Compared to the control condition, participants in the present study had more parasympathetic activity during self-affirmation writing exercise (higher HF-HRV and RSA) and in response to the negative images in the self-affirmation condition (higher RSA).

In addition to the self-affirmation manipulation used in this study, self-reported affirmational thinking was found to be associated with higher self-esteem, optimism, and one's perceived worthiness in a group. More affirmational thinking was also related to higher levels of self-worth after the writing exercises, more perceived meaningfulness of the tasks, less negative affective responses, and lower perceived stress levels. These findings were consistent with those 
of past research in showing that self-affirmation correlates with other positive self-resources, such as self-esteem, optimism, and one's perceived worthiness as a group member, and serves as a stress buffer (Keough \& Markusm, 1998; Taylor \& Sherman, 2008). The connections between self-affirmation and self-resources are also related to positive psychology and well-being research, particularly to those that focused on constructs such as self-control, self-efficacy, prosocial feelings (e.g., love, connectedness), self-compassion, and subjective well-being (Howell, 2017). Research has shown that self-affirmation can increase self-efficacy (Epton \& Harris, 2008), prosocial feelings and behaviors (Thomaes, Bushman, de Castro, \& Reijntjes, 2012), and self-compassion (Lindsay \& Creswell, 2014). Moreover, Nelson, Fuller, Choi, and Lyubomirsky (2014) also found that self-affirmation led to both greater hedonic (i.e., balance between positive and negative affect) and eudaimonic (i.e., feelings of self-control, connectedness, and competence, purpose in life, and flow experience) well-being, suggesting its beneficial effects in enhancing positive aspects of self and perceived meaningfulness or purpose of life.

In the present study, the order of the conditions was counterbalanced, and the order significantly interacted with HR during the writing exercises, PA after the writing exercises, as well as PA and vigor scores after IAPS image presentations. These patterns showed that regardless of which condition was presented first (control or self-affirmation), participants' HR, PA, and vigor scores dropped from the control to self-affirmation condition and from the selfaffirmation to control condition. Furthermore, in regard to the magnitude of the decrease between the first and second conditions, participants who went through the self-affirmation condition first had larger decreases in HR and PA. The reasons behind these results were unclear. The decrease in PA and vigor scores may have been due to the length of the experiment and/or 
the tasks participants were asked to complete. The drop in HR may be associated with the increased familiarity with the task, which may have led to less physiological arousal in the second writing exercise compared to the first. The significant differences between the magnitudes of the drop in PA may be related to the content of the writing exercise. The magnitudes were greater for those who went from the more meaningful writing exercise (selfaffirmation) to the less meaningful one (control). However, these are speculations, and the cause of the interaction effects was not clear.

\section{Future Research}

The present study suggests the usefulness of self-affirmation for increasing parasympathetic activity and for coping with negative emotion. Although the self-affirmation task used in this study was fairly easy and short ( $5 \mathrm{~min})$, immediate beneficial effects were found. By focusing on, and writing about, one's core value, benefits from the practice of selfaffirmation in terms of cardiovascular activity and affective responses may be immediately realized. Duration of the self-affirmation practice, more specifically whether similar benefits can still be seen as the time spent on writing one's value decreases (or increases) is a potential research topic for future studies. Future research may also consider using a longitudinal design in examining the potential long-term beneficial effects of self-affirmation on cardiovascular responses when it is practiced frequently. Furthermore, consistent with most past self-affirmation research, the present study asked participants to write about their top-ranked value. Cohen et al. (2000) argued that writing about lowest ranked value could still be self-affirming in the process. Researchers may be interested in exploring whether non-top-ranked values may produce same results with similar effect sizes. 
Research has shown the self-affirmation's impacts on positive attributes and selfresources, suggesting self-affirmation's relevance to well-being research (Howell, 2017). However, Howell (2017) argued that self-affirmation has been under-recognized by the positive psychology field; researchers may wish to investigate the association between self-affirmation and well-being interventions. The relationships between trait affirmational thinking and other trait self-resources examined in the present study were correlational, which limited the ability to draw cause-and-effect conclusions. State (in addition to trait) self-esteem and optimism may need to be assessed in future research to examine whether more affirmational thinking significantly increased state self-resources. Moreover, recovery rates of HR to the images could not be examined due to the large fluctuations in the second to second HR. Modification of the method used to collect HR during and following the IAPS image presentations may be needed in future research.

\section{Conclusion}

The findings of the present study may provide useful insight on the immediate effects of self-affirmation, as no studies have used HF-HRV and RSA in examining self-affirmation's impact on vagal tone. Moreover, the present study is one of the few that have examined the cardiovascular responses both during and consequent to the practice of self-affirmation as well as to the negative emotion induction. The present study showed that self-affirmation can help people cope with negative emotion and increase parasympathetic activity. Affirmational thinking was also found to be associated with self-resources, such as self-esteem, optimism, and one's perceived worthiness in a group. Self-affirmation is beneficial to one's physiological and psychological well-being. Not only are the effects of self-affirmation valuable and quick, it is also easy to practice with practically no cost. 


\section{References}

Appelhans, B. M., \& Luecken, L. J. (2006). Heart rate variability as an index of regulated emotional responding. Review of General Psychology, 10(3), 229-240. doi:10.1037/10892680.10.3.229

Benjamini, Y. and Hochberg, Y. (1995). Controlling the false discovery rate: A practical and powerful approach to multiple testing. Journal of the Royal Statistical Society, 57(1), 289-300.

Bradley, M. M. (2000). Emotion and motivation. In J. T. Cacioppo, L. G. Tassinary, \& G. G. Berntson (Eds.), Handbook of psychophysiology (2nd ed., pp. 602-642). Cambridge, UK: Cambridge University Press.

Bradley, M. M., \& Lang, P. J. (1994). Measuring emotion: The Self-Assessment Manikin and the semantic differential. Journal of Behavior Therapy and Experimental Psychiatry, 25(1), 49-59. doi:10.1016/0005-7916(94)90063-9

Breslow, A. S., Brewster, M. E., Velez, B. L., Wong, S., Geiger, E., \& Soderstrom, B. (2015). Resilience and collective action: Exploring buffers against minority stress for transgender individuals. Psychology of Sexual Orientation and Gender Diversity, 2(3), 253-265. doi:10.1037/sgd0000117

Butler, E. A., Wilhelm, F. H., \& Gross, J. J. (2006). Respiratory sinus arrhythmia, emotion, and emotion regulation during social interaction. Psychophysiology, 43(6), 612-622. doi:10.1111/j.1469-8986.2006.00467.x

Charlson, M. E., Boutin-Foster, C., Mancuso, C. A., Peterson, J. C., Ogedegbe, G., Briggs, W. M., ... Allegrante, J. P. (2007). Randomized controlled trials of positive affect and selfaffirmation to facilitate healthy behaviors in patients with cardiopulmonary diseases: 
Rationale, trial design, and methods. Contemporary Clinical Trials, 28(6), 748-762. doi:10.1016/j.cct.2007.03.002

Chen, W. (2012). Immediate Effects of Positive Self-Talk on Stress and Speech Performance. (Master's thesis). Retrieved from SJSU ScholarWorks. (4191)

Cohen, G. L., Aronson, J., \& Steele, C. M. (2000). When beliefs yield to evidence: Reducing biased evaluation by affirming the self. Personality and Social Psychology Bulletin, 26(9), 1151-1164. doi:10.1177/01461672002611011

Cohen, G. L., Garcia, J., Purdie-Vaughns, V., Apfel, N., \& Brzustoski, P. (2009). Recursive processes in self-affirmation: Intervening to close the minority achievement gap. Science, 324(5925), 400-403. doi:10.1126/science.1170769

Cohen, G. L., \& Sherman, D. K. (2014). The psychology of change: Self-affirmation and social psychological intervention. Annual Review of Psychology, 65333-371.

doi:10.1146/annurev-psych-010213-115137

Creswell, J. D., Welch, W. T., Taylor, S. E., Sherman, D. K., Gruenewald, T. L., \& Mann, T. (2005). Affirmation of personal values buffers neuroendocrine and psychological stress responses. Psychological Science, 16(11), 846-851. doi:10.1111/j.14679280.2005.01624.x

Critcher, C. R., \& Dunning, D. (2015). Self-affirmations provide a broader perspective on selfthreat. Personality and Social Psychology Bulletin, 41(1), 3-18. doi:10.1177/0146167214554956

Critcher, C. R., Dunning, D., \& Armor, D. A. (2010). When self-affirmations reduce defensiveness: Timing is key. Personality and Social Psychology Bulletin, 36(7), 947959. doi: $10.1177 / 0146167210369557$ 
Crocker, J., Niiya, Y., \& Mischkowski, D. (2008). Why does writing about important values reduce defensiveness? Self-affirmation and the role of positive other-directed feelings. Psychological Science, 19(7), 740-747. doi:10.1111/j.1467-9280.2008.02150.x

Epton, T., \& Harris, P. R. (2008). Self-affirmation promotes health behavior change. Health Psychology, 27(6), 746-752. http://dx.doi.org/10.1037/0278-6133.27.6.746

Epton, T., Harris, P. R., Kane, R., van Koningsbruggen, G. M., \& Sheeran, P. (2015). The impact of self-affirmation on health-behavior change: A meta-analysis. Health Psychology, 34(3), 187-196. doi:10.1037/hea0000116

Galinsky, A. D., Stone, J., \& Cooper, J. (2000). The reinstatement of dissonance and psychological discomfort following failed affirmation. European Journal of Social Psychology, 30(1), 123-147. doi:10.1002/(SICI)1099-0992(200001/02)30:1<123::AIDEJSP981>3.0.CO;2-T

Gray-Little, B., Williams, V. L., \& Hancock, T. D. (1997). An item response theory analysis of the Rosenberg Self-Esteem Scale. Personality and Social Psychology Bulletin, 23(5), 443-451. doi:10.1177/0146167297235001

Guyenet, P. G. (2006). The sympathetic control of blood pressure. Nature Reviews Neuroscience, 7(5), 335-346. doi:10.1038/nrn1902

Harber, K. (1995). Sources of Validation Scale. Unpublished scale.

Harris, P. R., Brearley, I., Sheeran, P., Barker, M., Klein, W. P., Creswell, J. D., \& ... Bond, R. (2014). Combining self-affirmation with implementation intentions to promote fruit and vegetable consumption. Health Psychology, 33(7), 729-736. doi:10.1037/hea0000065 
Harris, P. R., Mayle, K., Mabbott, L., \& Napper, L. (2007). Self-affirmation reduces smokers' defensiveness to graphic on-pack cigarette warning labels. Health Psychology, 26(4), 437-446. doi:10.1037/0278-6133.26.4.437

Harris, P. R., \& Napper, L. (2005). Self-affirmation and the biased processing of threatening health-risk information. Personality and Social Psychology Bulletin, 31(9), 1250-1263. doi: $10.1177 / 0146167205274694$

Howell, A. J. (2017). Self-affirmation theory and the science of well-being. Journal of Happiness Studies, 18(1), 293-311. http://dx.doi.org/10.1007/s10902-016-9713-5

Keough, K. A., \& Markus, H. R. (1998). On being well: The role of the self in building the bridge from philosophy to biology. Psychological Inquiry, 9(1), 49-53. doi:10.1207/s15327965pli0901_7

Koole, S. L., Smeets, K., van Knippenberg, A., \& Dijksterhuis, A. (1999). The cessation of rumination through self-affirmation. Journal of Personality and Social Psychology, 77(1), 111-125. doi:10.1037/0022-3514.77.1.111

Lang, P. J. (1980). Behavioral treatment and bio-behavioral assessment: computer applications. In J. B. Sidowski, J. H. Johnson, \& T. A. Williams (Eds.), Technology in mental health care delivery systems (pp. 119-137). Norwood, NJ: Ablex.

Lang, P.J., Bradley, M.M., \& Cuthbert, B.N. (2005). International Affective Picture System (IAPS): Affective ratings of pictures and instruction manual. Technical Report A-6. University of Florida, Gainesville, FL.

Lannin, D. G. (2012). The effect of self-affirmation on stigma associated with seeking psychological help (Order No. 1531568). Available from ProQuest Dissertations \& Theses Full Text: The Sciences and Engineering Collection. (1269693906). 
Lindsay, E. K., \& Creswell, J. D. (2014). Helping the self help others: Self-affirmation increases self-compassion and pro-social behaviors. Frontiers in Psychiatry, 5(421), 1-9. doi: 10.3389/fpsyg.2014.0042

Liu, T. J., \& Steele, C. M. (1986). Attributional analysis as self-affirmation. Journal of Personality and Social Psychology, 51(3), 531-540. doi:10.1037/0022-3514.51.3.531

Lovibond, P. F., \& Lovibond, S. H. (1995). The structure of negative emotional states: Comparison of the Depression Anxiety Stress Scales (DASS) with the Beck Depression and Anxiety Inventories. Behaviour Research and Therapy, 33(3), 335-343. doi:10.1016/0005-7967(94)00075-U

Luhtanen, R., \& Crocker, J. (1992). A collective self-esteem scale: Self-evaluation of one's social identity. Personality and Social Psychology Bulletin, 18(3), 302-318. doi:10.1177/0146167292183006

McQueen, A., \& Klein, W. P. (2006). Experimental manipulations of self-affirmation: A systematic review. Self and Identity, 5(4), 289-354. doi:10.1080/15298860600805325

Miyake, A., Kost-Smith, L. E., Finkelstein, N. D., Pollock, S. J., Cohen, G. .., \& Ito, T. A. (2010). Reducing the gender achievement gap in college science: A classroom study of values affirmation. Science, 330(6008), 1234-1237. doi:10.1126/science.1195996

Morris, J. D. (1995). Observations: SAM: The self-assessment manikin: An efficient crosscultural measurement of emotional response. Journal of Advertising Research, 35(6), 6368.

Nelson, S. K., Fuller, J. A. K., Choi, I., \& Lyubomirsky, S. (2014). Beyond self-protection: Selfaffirmation benefits hedonic and eudaimonic well-being. Personality and Social Psychology Bulletin, 40(8), 998-1011. http://dx.doi.org/10.1177/0146167214533389 
Robins, R. W., Hendin, H. M., \& Trzesniewski, K. H. (2001). Measuring global self-esteem: Construct validation of a single-item measure and the Rosenberg Self-Esteem Scale. Personality and Social Psychology Bulletin, 27(2), 151-161. doi: $10.1177 / 0146167201272002$

Rosenberg, M. (1989). Society and the adolescent self-image (rev. ed.). Middletown, CT, England: Wesleyan University Press.

Ruiter, M. E. (2011). Self-affirmation and working memory capacity's influence on adherence to brief behavioral insomnia treatment. Dissertation Abstracts International, 73, 1234.

Scheier, M. F., Carver, C. S., \& Bridges, M. W. (1994). Distinguishing optimism from neuroticism (and trait anxiety, self-mastery, and self-esteem): A reevaluation of the Life Orientation Test. Journal of Personality and Social Psychology, 67(6), 1063-1078. doi:10.1037/0022-3514.67.6.1063

Sherman, D. K. (2013). Self-affirmation: Understanding the effects. Social and Personality Psychology Compass, 7(11), 834-845. doi:10.1111/spc3.12072

Sherman, D. K., Bunyan, D. P., Creswell, J. D., \& Jaremka, L. M. (2009). Psychological vulnerability and stress: The effects of self-affirmation on sympathetic nervous system responses to naturalistic stressors. Health Psychology, 28(5), 554-562. doi:10.1037/a0014663

Sherman, D. K., \& Cohen, G. L. (2006). The psychology of self-defense: Self-affirmation theory. In M. P. Zanna, M. P. Zanna (Eds.), Advances in experimental social psychology, Vol 38 (pp. 183-242). San Diego, CA, US: Elsevier Academic Press. doi:10.1016/S00652601(06)38004-5 
Sherman, D. K., Hartson, K. A., Binning, K. R., Purdie-Vaughns, V., Garcia, J., Taborsky-Barba, S., \& ... Cohen, G. L. (2013). Deflecting the trajectory and changing the narrative: How self-affirmation affects academic performance and motivation under identity threat. Journal of Personality and Social Psychology, 104(4), 591-618. doi:10.1037/a0031495

Sherman, D. K., \& Kim, H. S. (2005). Is there an 'I' in 'team'? The role of the self in groupserving judgments. Journal of Personality and Social Psychology, 88(1), 108-120. doi:10.1037/0022-3514.88.1.108

Sherman, D. K., Nelson, L. D., \& Steele, C. M. (2000). Do messages about health risks threaten the self? Increasing the acceptance of threatening health messages via self-affirmation. Personality and Social Psychology Bulletin, 26(9), 1046-1058.

doi:10.1177/01461672002611003

Siegel, P. A., Scillitoe, J., \& Parks-Yancy, R. (2005). Reducing the tendency to self-handicap: The effect of self-affirmation. Journal of Experimental Social Psychology, 41(6), 589597. doi:10.1016/j.jesp.2004.11.004

Smith, B. W., Dalen, J., Wiggins, K., Tooley, E., Christopher, P., \& Bernard, J. (2008). The Brief Resilience Scale: Assessing the ability to bounce back. International Journal of Behavioral Medicine, 15(3), 194-200. doi:10.1080/10705500802222972

Steele, C. M. (1988). The psychology of self-affirmation: Sustaining the integrity of the self. In L. Berkowitz, L. Berkowitz (Eds.), Advances in experimental social psychology, Vol. 21: Social psychological studies of the self: Perspectives and programs (pp. 261-302). San Diego, CA, US: Academic Press.

Steele, C. M., \& Liu, T. J. (1983). Dissonance processes as self-affirmation. Journal of Personality and Social Psychology, 45(1), 5-19. doi:10.1037/0022-3514.45.1.5 
Tang, D., \& Schmeichel, B. J. (2015). Self-affirmation facilitates cardiovascular recovery following interpersonal evaluation. Biological Psychology, 104108-115. doi:10.1016/j.biopsycho.2014.11.011

Taylor, S. E., Burklund, L. J., Eisenberger, N. I., Lehman, B. J., Hilmert, C. J., \& Lieberman, M. D. (2008). Neural bases of moderation of cortisol stress responses by psychosocial resources. Journal of Personality and Social Psychology, 95(1), 197-211. doi:10.1037/0022-3514.95.1.197

Taylor, S. E., \& Gollwitzer, P. M. (1995). Effects of mindset on positive illusions. Journal of Personality and Social Psychology, 69(2), 213-226. doi:10.1037/0022-3514.69.2.213

Taylor, S. E., Lerner, J. S., Sherman, D. K., Sage, R. M., \& McDowell, N. K. (2003). Portrait of the self-enhancer: Well adjusted and well liked or maladjusted and friendless? Journal of Personality and Social Psychology, 84(1), 165-176. doi:10.1037/0022-3514.84.1.165

Taylor, S. E., \& Sherman, D. K. (2008). Self-enhancement and self-affirmation: The consequences of positive self-thoughts for motivation and health. In J. Y. Shah, W. L. Gardner, J. Y. Shah, W. L. Gardner (Eds.), Handbook of motivation science (pp. 57-70). New York, NY, US: Guilford Press.

Terry, P. C., Lane, A. M., \& Fogarty, G. J. (2003). Construct validity of the Profile of Mood States-Adolescents for use with adults. Psychology of Sport and Exercise, 4(2), 125-139. doi:10.1016/S1469-0292(01)00035-8

Terry, P. C., Lane, A. M., Lane, H. J., \& Keohane, L. (1999). Development and validation of a mood measure for adolescents. Journal of Sports Sciences, 17(11), 861-872.

Tesser, A. (2000). On the confluence of self-esteem maintenance mechanisms. Personality and Social Psychology Review, 4(4), 290-299. doi:10.1207/S15327957PSPR0404_1 
Thomaes, S., Bushman, B. J., de Castro, B. O., \& Reijntjes, A. (2012). Arousing “gentle passions" in young adolescents: Sustained experimental effects of value affirmations on prosocial feelings and behaviors. Developmental Psychology, 48(1), 103-110. doi:http://dx.doi.org/10.1037/a0025677

Thomsen, L., Sidanius, J., \& Fiske, A. P. (2007). Interpersonal leveling, independence, and selfenhancement: A comparison between Denmark and the US, and a relational practice framework for cultural psychology. European Journal of Social Psychology, 37(3), 445469. doi:10.1002/ejsp.366

Van den Bos, K. (2001). Reactions to perceived fairness: The impact of mortality salience and self-esteem on ratings of negative affect. Social Justice Research, 14(1), 1-23. doi:10.1023/A:1012501506803

Watson, D., Clark, L. A., \& Tellegen, A. (1988). Development and validation of brief measures of positive and negative affect: The PANAS scales. Journal of Personality and Social Psychology, 54(6), 1063-1070. doi:10.1037/0022-3514.54.6.1063 


\section{Appendix A}

\section{Sources of Validation Scale}

Ranking of Personal Characteristics and Values:

Below is a list of characteristics and values, some of which maybe important to you, some of which may be unimportant. Please rank these values and qualities in order of their importance to you, from 1 to $11(1=$ most important item, $11=$ least important item $)$. Use each number only once.

Artistic skills/aesthetic appreciation

Sense of humor

Relations with friends/family

Spontaneity/living life in the moment

Social skills

Athletics

Musical ability/appreciation

Physical attractiveness

Creativity

Business/managerial skills

Romantic values

Source: Harber (1995) 


\section{Appendix B}

\section{Value Affirmation Writing Exercise}

Your top-ranked value/quality:

You have 5 minutes to write about your top-ranked value/quality. Don't worry about finding the perfect words or phrases while writing. The purpose of this writing exercise is to focus on your feelings and thoughts about your top-ranked value. Please write about why this value/quality is important to you and how it makes you feel good about yourself. In addition, describe a time when your top-ranked value/quality was particularly important to you. Be specific.

Sources: Charlson et al. (2007); Cohen et al. (2000); Harris \& Napper (2005); Ruiter (2011); Sherman et al. (2000) 


\section{Appendix C}

\section{Jelly Bean Flavor Scale}

Ranking of jelly bean Flavors:

Below is a list of jelly bean flavors, some of which may seem tasty to you, some of which may not seem tasty. Please rank these jellybeans in order of tastiness, from 1-12 $(1=$ most tasty jellybean flavor, 12 = least tasty jellybean flavor). Use each number only once.

B__ Blueberry/Vanilla Swirl
Buttered Popcorn
Peppermint Tea
Caribbean Punch
Pink Lemonade
Peanut Butter\& Jelly
Watermelon
Caramel Apple
Saltine Cracker
Tartar Sauce
Strawberry
Mango

Source: Lannin (2012) 


\section{Appendix D}

Jelly Bean Writing Exercise

Your third-ranked jelly bean:

Your fourth-ranked jell bean:

You have 5 minutes to write about the third and fourth tastiest jelly beans you ranked. Don't worry about finding the perfect words or phrases while writing. The purpose of this writing exercise is to focus on your thoughts about these two jelly bean flavors. Please describe the flavors of the two jelly beans you ranked as the third and fourth tastiest. Be specific.

Source: Lannin (2012) 


\section{Appendix E}

Examples of International Affective Picture System (IAPS) Images

Positive:

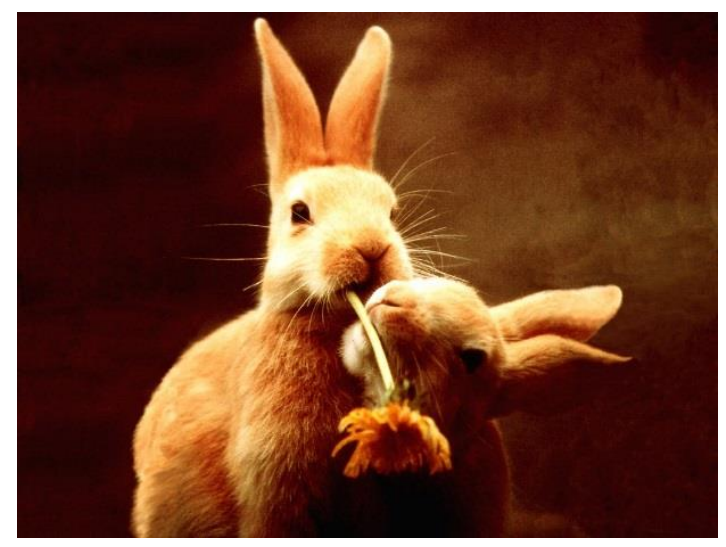

Negative:

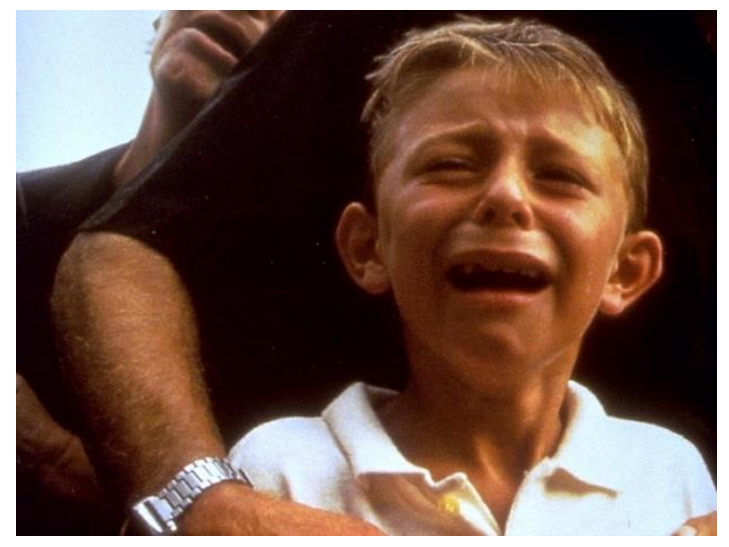

Neutral:

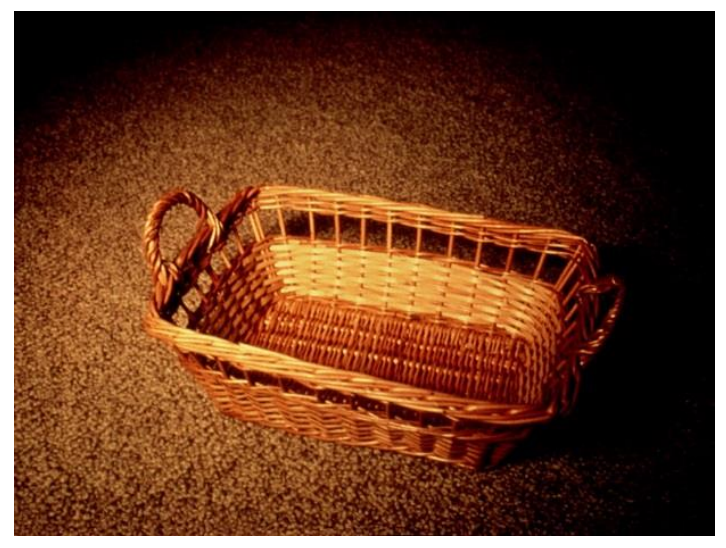

Source: Lang et al. (2005) 


\title{
Appendix F
}

\section{Self-Assessment Manikin (SAM)}

\author{
Valence Scale
}

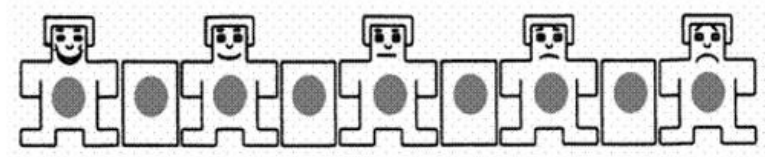

$\begin{array}{lllllllllll}\text { Positive / Pleasant } & 1 & 2 & 3 & 4 & 5 & 6 & 7 & 8 & 9 & \text { Negative / Unpleasant }\end{array}$

\section{Arousal Scale}

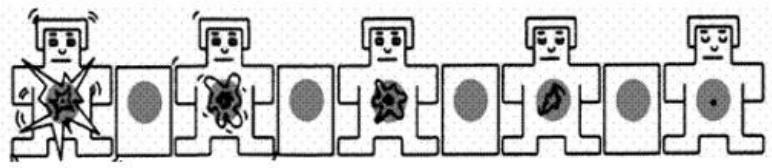

$\begin{array}{lllllllllll}\text { Excited / Anxious } & 1 & 2 & 3 & 4 & 5 & 6 & 7 & 8 & 9 & \text { Calm }\end{array}$

Dominance Scale

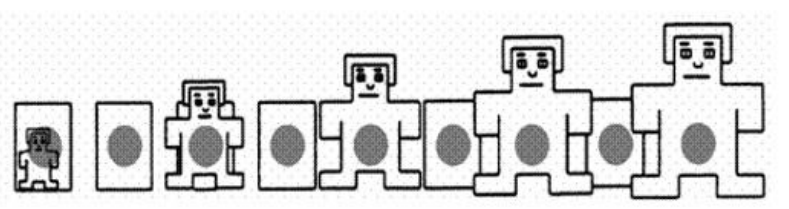

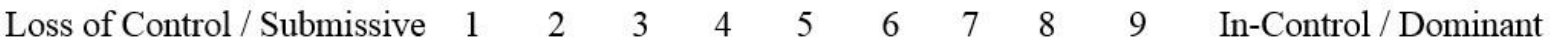

Sources: Bradley \& Lang (1994); Lang (1980); Lang et al. (2005) 


\section{Appendix G}

\section{Cardiovascular Health History Questionnaire}

Please answer the following questions about your cardiovascular health, possible medications you are currently taking, and the history of cardiovascular health in your family, and your fitness level. You may circle all that apply. Remember, your responses will be kept confidential.

1. Do you have history of any of the following cardiovascular problems:

a. Hypertension (high blood pressure)

b. Coronary Artery Disease

c. Atherosclerosis

d. Stroke

e. Myocardial Infarction (heart attack)

f. Aortic stenosis

g. Mitral regurgitate

h. Any other cardiovascular disease not listed above (please, indicate the name of this disease)

i. I DO NOT HAVE ANY CARDIOVASDULAR PROBLEMS

2. Does your biological mother have any of the following cardiovascular problems:

a. Hypertension (high blood pressure)

b. Coronary Artery Disease

c. Atherosclerosis

d. Stroke

e. Myocardial Infarction (heart attack)

f. Aortic stenosis

g. Mitral regurgitate

h. Any other cardiovascular disease not listed above (please, indicate the name of this disease)

i. MY MOTHER DOES NOT HAVE ANY CARDIOVASCULAR PROBLEMS

3. Does your biological father have any of the following cardiovascular problems:

a. Hypertension (high blood pressure)

b. Coronary Artery Disease

c. Atherosclerosis

d. Stroke

e. Myocardial Infarction (heart attack)

f. Aortic stenosis

g. Mitral regurgitate

h. Any other cardiovascular disease not listed above (please, indicate the name of this disease)

i. MY FATHER DOES NOT HAVE ANY CARDIOVASCULAR PROBLEMS 
4. Does anyone in your immediate family have any of the following cardiovascular problems (please, circle all that apply and write who this family member is, e.g., sister/brother/aunt/uncle, etc.):

a. Hypertension (Family member:

b. Coronary Artery Disease (Family member:

c. Atherosclerosis (Family member:

d. Stroke (Family member:

e. Myocardial Infarction (heart attack) (Family member:

f. Aortic stenosis (Family member:

g. Mitral regurgitate Family member:

$h$. Any other cardiovascular disease not listed above (please, indicate the name of this disease) (Family member: )

$i$. NONE OF MY RELATIVES HAS ANY CARDIOVASCULAR PROBLEMS

5. Do you have any of the respiratory problems?
a. Yes
b. No

6. If you answered yes, please indicate what type of severe respiratory problem do you have.

7. Do you currently take any of the following medications in any form:

a. Dexamethasone

b. Steroids (e.g., prednisone, or inhaled steroids for asthma)

c. Diet pills (please, indicate the name of the pill:

d. Beta-blockers

e. Histamines

f. Decongestants

g. Any other medications not listed above (please, write a name of this medication)

h. I DO NOT CURRENTLY TAKE ANY MEDICATIONS

8. Do you smoke?
a. Yes
b. No

9. If you smoke, how many cigarettes per day do you smoke per day?

10. How much caffeine/caffeinated beverages have you had TODAY?

a. How many cups of coffee have you had today?

b. What is the amount of coke have you had today?

c. Please, list other caffeinated beverages/foods you have had today 
11. How much caffeine/caffeinated beverages do you USUALLY consume per day?

a. How many cups of coffee do you have per day?

b. What is the amount of coke you have per day?

c. Please, list other caffeinated beverages/foods you may have during the day

12. How many times a week do you exercise:
a. Less than once a week
b. Once a week
c. Twice a week
d. Three times a week
e. Four or more times a week

13. How vigorous is your exercise (the examples are taken from www.fitday.com):

a. Very intense (such as fast jogging, weight lifting, etc.)

b. Moderate (such as slow jogging, fast walk)

c. Light (such as walking to school)

d. If you are unsure on how to classify your exercise, please, provide its description below: Exercise: 


\section{Appendix $\mathrm{H}$}

\section{Rosenberg Self-Esteem Scale (RSES)}

Below is a list of statements dealing with your general feelings about yourself. Please indicate how strongly you agree or disagree with each statement.

1. On the whole, I am satisfied with myself.

Strongly Agree Agree Disagree Strongly Disagree

2. At times I think I am no good at all.

Strongly Agree Agree Disagree Strongly Disagree

3. I feel that I have a number of good qualities.

Strongly Agree Agree Disagree Strongly Disagree

4. I am able to do things as well as most other people.

Strongly Agree Agree Disagree Strongly Disagree

5. I feel I do not have much to be proud of.

$\begin{array}{llll}\text { Strongly Agree } & \text { Agree } & \text { Disagree } & \text { Strongly Disagree }\end{array}$

6. I certainly feel useless at times.

Strongly Agree Agree Disagree Strongly Disagree

7. I feel that I'm a person of worth, at least on an equal plane with others.

Strongly Agree Agree Disagree Strongly Disagree

8. I wish I could have more respect for myself.

Strongly Agree Agree Disagree $\quad$ Strongly Disagree

9. All in all, I am inclined to feel that I am a failure.
Strongly Agree
Agree
Disagree
Strongly Disagree

10. I take a positive attitude toward myself.

Strongly Agree Agree Disagree $\quad$ Strongly Disagree

\section{Scoring:}

1. Give "Strongly Disagree" 1 point, "Disagree" 2 points, "Agree" 3 points, and "Strongly Agree" 4 points.

2. Items 2, 5, 6, 8, 9 are reverse scored.

3. Sum scores for all ten items. Keep scores on a continuous scale. Higher scores indicate higher self-esteem.

Source: Rosenberg (1989) 


\section{Appendix I}

\section{Collective Self-Esteem Scale (CSES)}

We are all members of different social groups or social categories. Some of such social groups or categories pertain to gender, race, religion, nationality, ethnicity, and socioeconomic class. We would like you to consider your memberships in those particular groups or categories, and respond to the following statements on the basis of how you feel about those groups and your memberships in them. There are no right or wrong answers to any of these statements; we are interested in your honest reactions and opinions. Please read each statement carefully, and respond by using the following scale from 1 to 7.

\begin{tabular}{|c|c|c|c|c|c|c|}
\hline $\begin{array}{c}\text { Strongly } \\
\text { Disagree }\end{array}$ & Disagree & $\begin{array}{c}\text { Disagree } \\
\text { Somewhat }\end{array}$ & Neutral & $\begin{array}{c}\text { Agree } \\
\text { Somewhat }\end{array}$ & Agree & $\begin{array}{c}\text { Strongly } \\
\text { Agree }\end{array}$ \\
\hline 1 & 2 & 3 & 4 & 5 & 6 & 7 \\
\hline
\end{tabular}

\begin{tabular}{|l|l|c|c|c|c|c|c|c|}
\hline 1. & $\begin{array}{l}\text { I am a worthy member of the social } \\
\text { groups I belong to. }\end{array}$ & 1 & 2 & 3 & 4 & 5 & 6 & 7 \\
\hline 2. & $\begin{array}{l}\text { I often regret that I belong to some of the } \\
\text { social groups I do. }\end{array}$ & 1 & 2 & 3 & 4 & 5 & 6 & 7 \\
\hline 3. & $\begin{array}{l}\text { Overall, my social groups are considered } \\
\text { good by others. }\end{array}$ & 1 & 2 & 3 & 4 & 5 & 6 & 7 \\
\hline 4. & $\begin{array}{l}\text { Overall, my group memberships have } \\
\text { very little to do with how I feel about } \\
\text { myself. }\end{array}$ & 1 & 2 & 3 & 4 & 5 & 6 & 7 \\
\hline 5. & $\begin{array}{l}\text { I feel I don't have much to offer to the } \\
\text { social groups I belong to. }\end{array}$ & 1 & 2 & 3 & 4 & 5 & 6 & 7 \\
\hline 6. & $\begin{array}{l}\text { In general, I'm glad to be a member of } \\
\text { the social groups I belong to. }\end{array}$ & 1 & 2 & 3 & 4 & 5 & 6 & 7 \\
\hline 7. & $\begin{array}{l}\text { Most people consider my social groups, } \\
\text { on the average, to be more ineffective } \\
\text { than other social groups. }\end{array}$ & 1 & 2 & 3 & 4 & 5 & 6 & 7 \\
\hline 8. & $\begin{array}{l}\text { The social groups I belong to are an } \\
\text { important reflection of who I am. }\end{array}$ & 1 & 2 & 3 & 4 & 5 & 6 & 7 \\
\hline 9. & $\begin{array}{l}\text { I am a cooperative participant in the } \\
\text { social groups I belong to. }\end{array}$ & 1 & 2 & 3 & 4 & 5 & 6 & 7 \\
\hline
\end{tabular}




\begin{tabular}{|l|l|c|c|c|c|c|c|c|}
\hline 10. & $\begin{array}{l}\text { Overall, I often feel that the social } \\
\text { groups of which I am a member are not } \\
\text { worthwhile. }\end{array}$ & 1 & 2 & 3 & 4 & 5 & 6 & 7 \\
\hline 11. & $\begin{array}{l}\text { In general, others respect the social } \\
\text { groups that I am a member of. }\end{array}$ & 1 & 2 & 3 & 4 & 5 & 6 & 7 \\
\hline 12. & $\begin{array}{l}\text { The social groups I belong to are } \\
\text { unimportant to my sense of what kind of } \\
\text { a person I am. }\end{array}$ & 1 & 2 & 3 & 4 & 5 & 6 & 7 \\
\hline 13. & $\begin{array}{l}\text { I often feel I'm a useless member of my } \\
\text { social groups. }\end{array}$ & 1 & 2 & 3 & 4 & 5 & 6 & 7 \\
\hline 14. & $\begin{array}{l}\text { I feel good about the social groups I } \\
\text { belong to. }\end{array}$ & 1 & 2 & 3 & 4 & 5 & 6 & 7 \\
\hline 15. & $\begin{array}{l}\text { In general, others think that the social } \\
\text { groups I am a member of are unworthy. }\end{array}$ & 1 & 2 & 3 & 4 & 5 & 6 & 7 \\
\hline 16. & $\begin{array}{l}\text { In general, belonging to social groups is } \\
\text { an important part of my self image. }\end{array}$ & 1 & 2 & 3 & 4 & 5 & 6 & 7 \\
\hline
\end{tabular}

\section{Scoring:}

1. Reversed code items $2,4,5,7,10,12,13$, and 15 :

$$
(1=7)(2=6)(3=5)(4=4)(5=3)(6=2)(7=1) \text {. }
$$

2. Sum the items to obtain four scores:
a. Membership: 1, 5, 9, and 13
b. Private: $2,6,10$, and 14
c. Public: $3,7,11$, and 15
d. Identity: 4, 8, 12, and 16

Source: Luhtanen \& Crocker (1992) 


\section{Appendix J}

\section{Revised Life Orientation Test (LOT-R)}

Using the scale below as a guide, indicate how much you agree with each statement below.

$0=$ Strongly Disagree

$1=$ Disagree

$2=$ Neutral

$3=$ Agree

$4=$ Strongly Agree

1. In uncertain times, I usually expect the best.

2. It's easy for me to relax.

3. If something can go wrong for me it will.

4. I am always optimistic about my future.

5. I enjoy my friends a lot.

6. It's important for me to keep busy.

7. I hardly ever expect things to go my way.

8. I don't get upset too easily.

9. I rarely count on good things happening to me.

10. Overall, I expect more good things to happen to me than bad.

\section{Scoring:}

1. Reverse code items 3, 7, and 9 prior to scoring: $(0=4)(1=3)(2=2)(3=1)(4=0)$.

2. Sum items $1,3,4,7,9,10$ to obtain an over score.

Note: Items 2, 5, 6, and 8 are filler items only.

Source: Scheier et al. (1994) 


\section{Appendix K}

How I See Myself (HSM)

For each of the qualities or skills below, we would like you to rate yourself in comparison to your peers. Specifically, we want you to think about how the average UWM college students of your age and gender rates on each of these qualities or skills, and then rate yourself in comparison. Please use the following scale to rate yourself:

$1=\underline{\text { Much worse }}$ than the average college student of my age and gender

$2=\underline{\text { Somewhat worse }}$ than the average college student of my age and gender

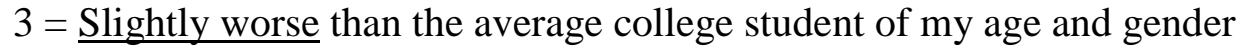

$4=$ About the same than the average college student of my age and gender

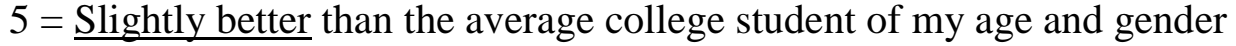

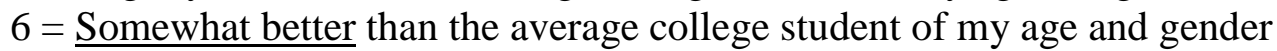

$7=\underline{\text { Much better }}$ than the average college student of my age and gender

Please read each item and fill in with the number that corresponds to your self-perception.

1.

2.

3.

4.

5 .

6.

7.

8.

9.

10.

11.
12. Manipulative

13.

14.

15.

16.

17.

18.

19.

20.

21.

22. Shy Impatient Lazy Academically able Self-respecting Sensitive to others Desire to achieve Difficulty making friends Lacking motivation Confident in ability to obtain personal goals

\section{Scoring:}

1. Reverse code items $2,4,5,8,11,12,14,17,19,20$, and 21:

$$
(1=7)(2=6)(3=5)(4=4)(5=3)(6=2)(7=1)
$$

2. A self-enhancement score is the mean of all the items

Source: Taylor \& Gollwitzer (1995) 


\section{Appendix L}

\section{Brief Resilience Scale (BRS)}

Please indicate the extent to which you agree with each of the following statements by using the following scale: $1=$ strongly disagree, $2=$ disagree, $3=$ neutral, $4=$ agree, $5=$ strongly agree. Please respond to each item by marking one number per row.

\begin{tabular}{|l|l|c|c|c|c|c|}
\hline & & $\begin{array}{c}\text { Strongly } \\
\text { Disagree }\end{array}$ & Disagree & Neutral & Agree & $\begin{array}{c}\text { Strongly } \\
\text { Agree }\end{array}$ \\
\hline 1 & $\begin{array}{l}\text { I tend to bounce back quickly after } \\
\text { hard times }\end{array}$ & 1 & 2 & 3 & 4 & 5 \\
\hline 2 & $\begin{array}{l}\text { I have a hard time making it } \\
\text { through stressful events }\end{array}$ & 1 & 2 & 3 & 4 & 5 \\
\hline 3 & $\begin{array}{l}\text { It does not take me long to recover } \\
\text { from a stressful event }\end{array}$ & 1 & 2 & 3 & 4 & 5 \\
\hline 4 & $\begin{array}{l}\text { It is hard for me to snap back when } \\
\text { something bad happens }\end{array}$ & 1 & 2 & 3 & 4 & 5 \\
\hline 5 & $\begin{array}{l}\text { I usually come through difficult } \\
\text { times with little trouble }\end{array}$ & 1 & 2 & 3 & 4 & 5 \\
\hline 6 & $\begin{array}{l}\text { I tend to take a long time to get over } \\
\text { set-backs in my life }\end{array}$ & 1 & 2 & 3 & 4 & 5 \\
\hline
\end{tabular}

\section{Scoring:}

1. Reverse code items 2,4 , and 6 .

2. A resilience score is the mean of all the items.

Source: Smith et al. (2008) 


\section{Appendix M}

\section{Depression Anxiety Stress Scale-21 (DASS-21)}

Please read each statement and circle a number $0,1,2$ or 3 that indicates how much the statement apply to you in general. There are no right or wrong answers. Do not spend too much time on any statement.

The rating scale is as follows:

0 Did not apply to me at all

1 Applied to me to some degree, or some of the time

2 Applied to me to a considerable degree, or a good part of time

3 Applied to me very much, or most of the time

1S I found it hard to wind down

$\begin{array}{llll}0 & 1 & 2 & 3\end{array}$

2A I was aware of dryness of my mouth

$\begin{array}{llll}0 & 1 & 2 & 3\end{array}$

3D I couldn't seem to experience any positive feeling at all

$\begin{array}{llll}0 & 1 & 2 & 3\end{array}$

4A I experienced breathing difficulty (e.g., excessively rapid breathing, $\quad \begin{array}{llllll}0 & 0 & 1 & 2 & 3\end{array}$ breathlessness in the absence of physical exertion)

5D I found it difficult to work up the initiative to do things

6S I tended to over-react to situations

$\begin{array}{llll}0 & 1 & 2 & 3\end{array}$

7A I experienced trembling (e.g., in the hands)

$\begin{array}{llll}0 & 1 & 2 & 3\end{array}$

8S I felt that I was using a lot of nervous energy

$\begin{array}{llll}0 & 1 & 2 & 3\end{array}$

9A I was worried about situations in which I might panic and make $\begin{array}{llll}0 & 1 & 2 & 3\end{array}$ a fool of myself

10D I felt that I had nothing to look forward to

$11 \mathrm{~S} \quad$ I found myself getting agitated

$\begin{array}{llll}0 & 1 & 2 & 3\end{array}$

12S I found it difficult to relax

$\begin{array}{llll}0 & 1 & 2 & 3\end{array}$

13D I felt down-hearted and blue

$\begin{array}{llll}0 & 1 & 2 & 3\end{array}$

$\begin{array}{llll}0 & 1 & 2 & 3\end{array}$

14S I was intolerant of anything that kept me from getting on with

$\begin{array}{llll}0 & 1 & 2 & 3\end{array}$ what I was doing

15A I felt I was close to panic

$\begin{array}{llll}0 & 1 & 2 & 3\end{array}$

16D I was unable to become enthusiastic about anything

$\begin{array}{llll}0 & 1 & 2 & 3\end{array}$ 
17D I felt I wasn't worth much as a person

$\begin{array}{llll}0 & 1 & 2 & 3 \\ 0 & 1 & 2 & 3 \\ 0 & 1 & 2 & 3 \\ 0 & 1 & 2 & 3 \\ 0 & 1 & 2 & 3\end{array}$

21D I felt that life was meaningless

\section{Scoring:}

1. $\mathrm{D}=$ Depression; $\mathrm{A}=$ Anxiety; $\mathrm{S}=$ Stress

2. The final score of each item groups (Depression, Anxiety, and Stress) needs to be multiplied by two.

a. Depression: sum items 3, 5, 10, 13, 16, 17, and 21 and multiply by two.

b. Anxiety: sum items 2, 4, 7, 9, 15, 19, and 20 and multiply by two.

c. Stress: sum items $1,6,8,11,12,14$, and 18 and multiply by two.

Source: Lovibond \& Lovibond (1995) 


\section{Appendix N}

\section{Perspective and Affirmational Thinking}

Using the following scales, please indicate how often you have the following thoughts or actions. Please circle one number per statement.

1. I think of one or more aspects of myself (beyond my academic self).

$\begin{array}{ccccccc}\text { Never } & \text { Rarely } & \text { Occasionally } & \text { Sometimes } & \text { Frequently } & \text { Usually } & \text { All the Time } \\ 1 & 2 & 3 & 4 & 5 & 6 & 7\end{array}$

2. I search for a sense of meaning.

$\begin{array}{ccccccc}\text { Never } & \text { Rarely } & \text { Occasionally } & \text { Sometimes } & \text { Frequently } & \text { Usually } & \text { All the Time } \\ 1 & 2 & 3 & 4 & 5 & 6 & 7\end{array}$

3. I identify various (non-academic) aspects of my identity.

$\begin{array}{ccccccc}\text { Never } & \text { Rarely } & \text { Occasionally } & \text { Sometimes } & \text { Frequently } & \text { Usually } & \text { All the Time } \\ 1 & 2 & 3 & 4 & 5 & 6 & 7\end{array}$

4. I emphasize why something has made my life affirming and whole.

$\begin{array}{ccccccc}\text { Never } & \text { Rarely } & \text { Occasionally } & \text { Sometimes } & \text { Frequently } & \text { Usually } & \text { All the Time } \\ 1 & 2 & 3 & 4 & 5 & 6 & 7\end{array}$

5. I think of aspects of my identity that extend beyond academics.

$\begin{array}{ccccccc}\text { Never } & \text { Rarely } & \text { Occasionally } & \text { Sometimes } & \text { Frequently } & \text { Usually } & \text { All the Time } \\ 1 & 2 & 3 & 4 & 5 & 6 & 7\end{array}$

6. I elaborate on why something has contributed to my worth as a person.

$\begin{array}{ccccccc}\text { Never } & \text { Rarely } & \text { Occasionally } & \text { Sometimes } & \text { Frequently } & \text { Usually } & \text { All the Time } \\ 1 & 2 & 3 & 4 & 5 & 6 & 7\end{array}$

7. I focus on one of more non-academic aspects of my identity.

$\begin{array}{ccccccc}\text { Never } & \text { Rarely } & \text { Occasionally } & \text { Sometimes } & \text { Frequently } & \text { Usually } & \text { All the Time } \\ 1 & 2 & 3 & 4 & 5 & 6 & 7\end{array}$


8. I construct a narrative that describes what has made my life meaningful.

$\begin{array}{ccccccc}\text { Never } & \text { Rarely } & \text { Occasionally } & \text { Sometimes } & \text { Frequently } & \text { Usually } & \text { All the Time } \\ 1 & 2 & 3 & 4 & 5 & 6 & 7\end{array}$

9. I identify one or more non-academic identities.

$\begin{array}{ccccccc}\text { Never } & \text { Rarely } & \text { Occasionally } & \text { Sometimes } & \text { Frequently } & \text { Usually } & \text { All the Time } \\ 1 & 2 & 3 & 4 & 5 & 6 & 7\end{array}$

10. I affirm my worth as a person.

$\begin{array}{ccccccc}\text { Never } & \text { Rarely } & \text { Occasionally } & \text { Sometimes } & \text { Frequently } & \text { Usually } & \text { All the Time } \\ 1 & 2 & 3 & 4 & 5 & 6 & 7\end{array}$

11. I remind myself the non-academic parts of who I am.

$\begin{array}{ccccccc}\text { Never } & \text { Rarely } & \text { Occasionally } & \text { Sometimes } & \text { Frequently } & \text { Usually } & \text { All the Time } \\ 1 & 2 & 3 & 4 & 5 & 6 & 7\end{array}$

12. I mull over what makes me feel positive.

$\begin{array}{ccccccc}\text { Never } & \text { Rarely } & \text { Occasionally } & \text { Sometimes } & \text { Frequently } & \text { Usually } & \text { All the Time } \\ 1 & 2 & 3 & 4 & 5 & 6 & 7\end{array}$

13. I appreciate I have multiple parts of who I am.

$\begin{array}{ccccccc}\text { Never } & \text { Rarely } & \text { Occasionally } & \text { Sometimes } & \text { Frequently } & \text { Usually } & \text { All the Time } \\ 1 & 2 & 3 & 4 & 5 & 6 & 7\end{array}$

14. I dwell on why something has been particularly meaningful to me.

$\begin{array}{ccccccc}\text { Never } & \text { Rarely } & \text { Occasionally } & \text { Sometimes } & \text { Frequently } & \text { Usually } & \text { All the Time } \\ 1 & 2 & 3 & 4 & 5 & 6 & 7\end{array}$

\section{Scoring:}

1. Perspective thinking: sum items $1,3,5,7,9,11$, and 13 .

2. Affirmational thinking: sum items $2,4,6,8,10,12$, and 14 .

Source: Critcher \& Dunning (2015) 


\section{Appendix $\mathrm{O}$}

\section{Demographic Questionnaire}

Below are a series of demographic questions. Please answer them as accurately as you can.

1. Age: years old

2. Gender (please select one): $\square$ Male $\quad \square$ Female $\quad \square$ Other:

3. Year in college (please select one):
$\square$ Freshman
$\square$ Sophomore
$\square$ Junior
$\square$ Senior
$\square$ Graduate Student
$\square$ Other:

4. Major(s):

5. Race (please select one):

$\square$ White/Caucasian (non-Hispanic)

$\square$ Asian/Pacific Islanders

$\square$ Black/African American

$\square$ Hispanic/Latino(a)

$\square$ Native American

$\square$ Biracial/Multiracial:

$\square$ Other: 


\section{Appendix $\mathrm{P}$}

Positive and Negative Affect Schedules (PANAS)

This scale consists of a number of words that describe different feelings and emotions. Read each item and then mark the appropriate answer in the space next to that word. Indicate to what extent you feel this way right now, that is, at the present moment. Use the following scale to record your answers.

\begin{tabular}{|c|c|c|c|c|}
\hline 1 & 2 & 3 & 4 & 5 \\
\hline $\begin{array}{c}\text { very slightly } \\
\text { or not at all }\end{array}$ & a little & moderately & quite a bit & extremely \\
\hline
\end{tabular}

\begin{tabular}{|c|c|}
\hline interested & irritable \\
\hline distressed & alert \\
\hline excited & ashamed \\
\hline upset & inspired \\
\hline strong & nervous \\
\hline guilty & determined \\
\hline scared & attentive \\
\hline hostile & jittery \\
\hline enthusiastic & active \\
\hline proud & afraid \\
\hline
\end{tabular}

\section{Scoring:}

1. Positive Affect: Sum Interested, Excited, Strong, Enthusiastic, Proud, Alert, Inspired, Determined, Attentive, and Active.

2. Negative Affect: Sum Distressed, Upset, Guilty, Scared, Hostile, Irritable, Ashamed, Nervous, Jittery, and Afraid

Source: Watson et al. (1988) 


\section{Appendix Q}

\section{Brunel Mood Scale (BMS)}

Below is a list of words that describe feelings. Please read each one carefully. Circle the number that best describes how you feel right now.

\begin{tabular}{|l|l|c|c|c|c|c|}
\hline & & Not at all & A little & Moderately & Quite a bit & Extremely \\
\hline 1 & Panicky & 1 & 2 & 3 & 4 & 5 \\
\hline 2 & Lively & 1 & 2 & 3 & 4 & 5 \\
\hline 3 & Confused & 1 & 2 & 3 & 4 & 5 \\
\hline 4 & Worn-out & 1 & 2 & 3 & 4 & 5 \\
\hline 5 & Depressed & 1 & 2 & 3 & 4 & 5 \\
\hline 6 & Downhearted & 1 & 2 & 3 & 4 & 5 \\
\hline 7 & Annoyed & 1 & 2 & 3 & 4 & 5 \\
\hline 8 & Exhausted & 1 & 2 & 3 & 4 & 5 \\
\hline 9 & Mixed-up & 1 & 2 & 3 & 4 & 5 \\
\hline 10 & Sleepy & 1 & 2 & 3 & 4 & 5 \\
\hline 11 & Bitter & 1 & 2 & 3 & 4 & 5 \\
\hline 12 & Unhappy & 1 & 2 & 3 & 4 & 5 \\
\hline 13 & Anxious & 1 & 2 & 3 & 4 & 5 \\
\hline 14 & Worried & 1 & 2 & 3 & 4 & 5 \\
\hline 15 & Energetic & 1 & 2 & 3 & 4 & 5 \\
\hline 16 & Miserable & 1 & 2 & 3 & 4 & 5 \\
\hline 17 & Muddled & 1 & 2 & 3 & 4 & 5 \\
\hline 18 & Nervous & 1 & 2 & 3 & 4 & 5 \\
\hline 19 & Angry & 1 & 2 & 3 & 4 & 5 \\
\hline 20 & Active & 1 & 2 & 3 & 4 & 5 \\
\hline 21 & Tired & 1 & 2 & 3 & 4 & 5 \\
\hline 22 & Bad-tempered & 1 & 2 & 3 & 4 & 5 \\
\hline 23 & Alert & 1 & 2 & 3 & 4 & 5 \\
\hline 24 & Uncertain & 1 & 2 & 3 & 4 & 5 \\
\hline
\end{tabular}

\section{Scoring:}

1. Anger: Angry, Annoyed, Bitter, and Bad-tempered (sum items 19, 7, 11, and 22).

2. Confusion: Confused, Mixed-up, Muddled, and Uncertain (sum items 3, 9, 17, and 24).

3. Depression: Depressed, Downhearted, Unhappy, and Miserable (sum items 5, 6, 12, and 16).

4. Fatigue: Worn-out, Exhausted, Sleepy, and Tired (sum items 4, 8, 10, and 21).

5. Tension: Panicky, Anxious, Worried, and Nervous (sum items 1, 13, 14, and 18).

6. Vigor: Lively, Energetic, Active, and Alert (sum items 2, 15, 20, and 23)

Sources: Terry et al. (2003); Terry et al. (1999) 


\section{Appendix R}

\section{Self-Worth Questionnaire (SWQ)}

Please indicate the extent to which you agree with each of the following statements about how you are feeling at this moment. Please respond to each statement by marking one number per item, using the scale from 1 (not at all) to 9 (extremely).

1. I currently feel proud.

$$
\begin{aligned}
& \text { not at all extremely }
\end{aligned}
$$

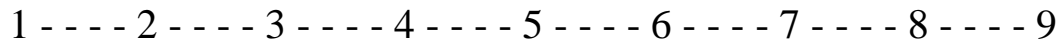

2. I currently feel confident.

$$
\text { not at all extremely }
$$$$
1---2---3---4--5---6---7---8--9
$$

3. Overall, I feel positively toward myself right now.

$$
\begin{aligned}
& \text { not at all extremely } \\
& 1---2---3--4---5---6--7---8---9
\end{aligned}
$$

4. I feel like a successful individual.

$$
\begin{aligned}
& \text { not at all extremely }
\end{aligned}
$$

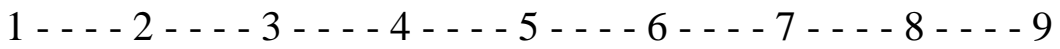

5. I currently feel pleased with myself.

$$
\begin{aligned}
& \text { not at all extremely } \\
& 1---2---3--4---5---6--7--18---9
\end{aligned}
$$

6. I feel good about myself right now.

$$
\begin{aligned}
& \text { not at all extremely } \\
& 1---2---3---4---5---6--7---8---9
\end{aligned}
$$

7. I feel very much like a person of worth.

$$
\text { not at all extremely }
$$

$$
1---2---3---4--5---6---7---8---9
$$

\section{Scoring:}

1. A self-worth score is the sum of all items.

Source: Critcher \& Dunning (2015) 


\section{Appendix $S$}

\section{Post-Writing Exercise Questionnaire}

Please answer the following questions about how you are feeling at this moment:

1. In general, how do you feel about yourself at this moment? (please circle one)

extremely negative neutral extremely positive

$$
1---2---3---4--5---6--7---8---9
$$

2. How personally meaningful did you find this writing exercise? (please circle one) not at all very much

$$
1---2---3---4---5---6---7
$$

3. How much would you agree that this writing exercise made you more aware of what you value? (please circle one)

strongly disagree strongly agree

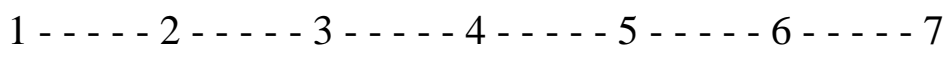

4. How much would you agree that this writing exercise made you think about how your value is personally important to you? (please circle one)

strongly disagree strongly agree

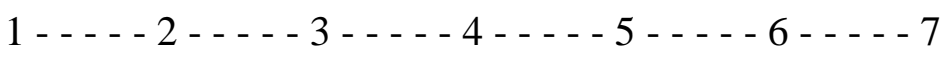

Sources: Cohen et al. (2000); Ruiter (2012); Siegal et al. (2005) 


\section{Appendix T}

IAPS Task Related Perceived Stress Questionnaire

1. How stressful have you found the image presentation to be? (Circle the number that applies to you)

\begin{tabular}{|c|c|c|c|c|}
\hline Not at all & A little & Moderately & Quite a bit & Extremely \\
\hline 1 & 2 & 3 & 4 & 5 \\
\hline
\end{tabular}

2. Was the image presentation cognitively demanding? (Circle the number that applies to you)

\begin{tabular}{|c|c|c|c|c|}
\hline Not at all & A little & Moderately & Quite a bit & Extremely \\
\hline 1 & 2 & 3 & 4 & 5 \\
\hline
\end{tabular}

3. How would you rate your stress level now? (Circle the number that applies to you)

\begin{tabular}{|c|c|c|c|c|}
\hline Not at all & A little & Moderately & Quite a bit & Extremely \\
\hline 1 & 2 & 3 & 4 & 5 \\
\hline
\end{tabular}

\section{Scoring:}

1. An IAPS task related perceived stress score is the sum of all three items.

Source: Chen (2012) 


\section{Appendix U}

\section{Evaluation of the Writings}

On a 7-point scale ranging from not at all to very, rate the essays on the following items:

1. Setting aside your own opinions and values, how self-affirmed would you estimate the writer of this passage to have been (at the end)?

2. How positive are they about themselves in the passage?

3. To what extent have they stuck to the task asked of them?

4. How important does the value they have selected appear to be to them?

Source: Harris \& Napper (2005) 


\section{Wei-Ju Chen}

Place of Birth: $\quad$ Taipei, Taiwan, Republic of China (R.O.C.)

Education: $\quad$ Ph.D., Experimental Psychology, August 2017

Concentration: Health and Social Psychology

Minors: Quantitative Methods; Cognition and Perception

University of Wisconsin-Milwaukee (UWM), Milwaukee, WI

M.A., Experimental Psychology, August 2012

San José State University (SJSU), San José, CA

B.S., Psychology, May 2010

Minor: Speech Communication

Graduated with Honors (Summa Cum Laude)

San José State University (SJSU), San José, CA

Language Skills: Fluent in Mandarin and English; conversational in Taiwanese.

Computer Skills: Proficient with

- Microsoft Office; Office Mix

- Statistical Package for the Social Sciences (SPSS)

- PROCESS macro for SPSS

- SuperLab

- Biopac software

- OmniSense software for BioHarness

- Kubios Heart Rate Variability (HRV) Analysis software

- Linguistic Inquiry and Word Count (LIWC)

- Qualtrics; SurveyMonkey

- Ezvid

- Windows Movie Maker

Honors, Awards,

Graduate Student Travel Awards, UWM, Milwaukee, WI, and Grants:

May 2017, March, 2016, \& April 2015

Travel Scholarship, SJSU, San José, CA, April 2013

Ronald G. Rabedeau Memorial Scholarship, SJSU, San José, CA, May 2012

College of Social Sciences Research Foundation Research Grant, SJSU, San José, CA, December 2011

Dean's Scholar, Annual Honors Convocation, SJSU, San José, CA, April 2011 
President's Scholar, Annual Honors Convocation, SJSU, San José, CA, April 2010 \& April 2009

SJSU Alumni Association Dean's Scholarship, SJSU, San José, CA, October 2009

Louise Barozzi Scholarship, SJSU, San José, CA, April 2009

Publications:

Manuscripts in Preparation:

\section{Conference Presentations:}

Toussaint, L. L., Lange, L., Chen, W., Hodge, M. H., O’Connor, M., \& Fleming, R. (2017). Control-oriented coping and stress responses during the acute phase of a technological accident. Journal of Applied Biobehavioral Research. (Volume, issue, and page numbers pending). doi:10.1111/jabr.12062

Nakajima, M., Chen, W., \& Fleming, R. (2017). Effects of unrecognized physiological residual arousal on emotional experience. Journal of Applied Biobehavioral Research. (Volume, issue, and page numbers pending). doi:10.1111/jabr.12103

Hodge, M., Crowley, O. V., Chen, W., Reddy, D., \& Fleming, R. (2017). Perceived technological risks predict willingness to eat irradiated spinach. Manuscript under review.

Levine, J., Fleming, R., Piedmont, J. I., Cain, S. M., \& Chen, W. (2016). Heart rate variability and generalized anxiety disorder during laboratoryinduced worry and aversive imagery. Journal of Affective Disorder, 205, 207-215. http://dx.doi.org/10.1016/j.jad.2016.07.019

Chen, W., \& Fleming, R. (2017). Effects of cardiovascular arousal on emotion. Manuscript in preparation.

Weinstein, B., Chen, W., Hodge, M., \& Fleming, R. (2017). Buffering and main effects of social support on traumatic evacuation stress. Manuscript in preparation.

Chen, W., Olin, K., Bieniewski, D., Maric, M., \& Fleming, R. (April, 2017). Effects of self-affirmation on emotion and cardiovascular responses. Poster session presented at the $89^{\text {th }}$ Annual Convention of Midwestern Psychological Association (MPA), Chicago, IL.

Chen, W., Maric, M., Olin, K., Bieniewski, D., Bowes, J., \& Fleming, R. (April, 2017). Beneficial effects of self-affirmation on heart rate variability, respiratory sinus arrhythmia, and emotion. Poster session presented at the $9^{\text {th }}$ University of Wisconsin-Milwaukee (UWM) Annual Research Symposium, Milwaukee, WI. 
Chen, W., Olin, K., Yang, N., Brookins, D., Jones, F., Hodge, M., \& Fleming, R. (May, 2016). Smoking affects cardiovascular reactivity during manipulations of emotion. Poster session presented at the $88^{\text {th }}$ Annual Convention of Midwestern Psychological Association (MPA), Chicago, IL.

Chen, W., Nakajima, M., \& Fleming, R. (April, 2016). Effects of autonomic arousal on emotion. Paper presented at the $18^{\text {th }}$ Association of Graduate Students in Psychology (AGSIP) Annual Research Symposium, Milwaukee, WI.

Chen, W., Ridel, T., Olin, K., Bowes, J., Brookins, D., \& Fleming, R. (April, 2016). Effects of self-affirmation on physiological arousal and psychological well-being. Poster session presented at the $8^{\text {th }}$ University of Wisconsin-Milwaukee (UWM) Annual Research Symposium, Milwaukee, WI.

Chen, W., Shepherd T., Bieniewski, D., Benkowski, O., Caputa, I., \& Fleming, R. (April, 2016). Optimism, personality traits, and depression. Poster session presented at the $8^{\text {th }}$ University of Wisconsin-Milwaukee (UWM) Annual Research Symposium, Milwaukee, WI.

Chen, W., Ridel, T., Peil, M., Lasner, N., \& Fleming, R. (May, 2015). Effects of cardiovascular arousal on emotional responses. Poster session presented at the $87^{\text {th }}$ Annual Convention of Midwestern Psychological Association (MPA), Chicago, IL.

Chen, W., Hoelter, C., Collins, S., Shanklin, A., \& Fleming, R. (May, 2015). Emotions, neuroticism, and cardiovascular reactivity. Poster session presented at the $87^{\text {th }}$ Annual Convention of Midwestern Psychological Association (MPA), Chicago, IL.

Chen, W., Andrews, C., \& Fleming, R. (April, 2015). Postural manipulation and emotion: how sitting and standing affect emotional response. Poster session presented at the $14^{\text {th }}$ University of Wisconsin System Annual Symposium, Milwaukee, WI.

Chen, W., Iwasaki, A., Hosoda, M., \& Chancellor-Freeland, C. (April, 2013). Perceived stress, cortisol, and self-talk. Poster session presented at the $93^{\text {rd }}$ Annual Convention of Western Psychological Association (WPA), Reno, NV.

Iwasaki, A., Chen, W., Hosoda, M., \& Chancellor-Freeland, C. (April, 2013). Effects of psychosocial stress and cortisol reactivity on multiple object tracking. Poster session presented at the $93^{\text {rd }}$ Annual Convention of Western Psychological Association (WPA), Reno, NV. 
Antonel, B., Akhtar, M., Iwasaki, A., Chen, W., Hosoda, M., \& Chancellor-Freeland, C. (April, 2012). The relationship between perceived stress and cortisol following the TSST. Poster session presented at the $92^{\text {nd }}$ Annual Convention of Western Psychological Association (WPA), Burlingame, CA.

Lee, W. \& Chen, W. (April, 2009). What do college students think about depression, eating disorders, and psychologists? Poster session presented at the Annual Conference of California Psychological Association (CPA), Oakland, CA.

\section{Research Experience:}

Laboratory Manager, October 2013-July 2017

Emotion, Stress, and Coping Laboratory, UWM, Milwaukee, WI

- Trained and supervised research assistants in data collection and analysis.

- Managed and worked with more than 50 research assistants in the lab over the course of 4 years.

- Conducted research studies related to physiological responses to stress and emotion, coping strategies, as well as psychological well-being.

- Created syntax files and spreadsheets with macros and formulas to compute cardiovascular measures, such as respiratory sinus arrhythmia.

- Collected and analyzed data using Biopac acquisition units, BioHarness devices, and software listed in the computer skills section.

- Generated online surveys using Qualtrics.

- Wrote manuscripts for publication and prepared presentations for conferences.

Data Analyst \& Research Assistant, May 2016-March 2017 Division of Academic Affairs \& College of Letters and Science, UWM, Milwaukee, WI

- Organized large and longitudinal data files from 23 semesters, Fall 2010 through Spring 2016.

- Conducted data analyses on academic records examining factors associated with students' success as well as predictors of educational outcomes with a focus on students who were PELLeligible.

- Collaborated with University of Information Technology Services in obtaining and organizing data files. 
Laboratory Manager, November 2010-May 2013

International Neuroeconomics Institute, Stress and Aging Research Lab, San José, CA

- Managed and organized the lab operations and research experiments.

- Trained and supervised research assistants in data collection and analysis.

- Managed and worked with more than 30 research assistants.

- Conducted studies related to the neuroendocrine stress responses.

- Analyzed saliva samples to assess cortisol and oxytocin levels using salivary cortisol and oxytocin enzyme immunoassay kits and bioassay software.

- Provided training to lab members on conducting bioassays.

- Wrote grant proposals to request funding for research.

Research Assistant, September 2008-January 2011

Counseling and Psychological Services, SJSU, San José, CA

- Co-developed the questionnaire to assess college students' attitudes on mental health related topics.

- Collected and analyzed data using Microsoft Excel and SPSS.

- Conducted presentations and workshops to increase mental health literacy and awareness.

Mandarin Back Translator, October 2009-December 2009 Psychology Department, SJSU, San José, CA

Project: Testing the validity of the Chinese five elements perspective on personality.

- Back-translated personality scales from Mandarin to English.

Teaching

Experience in

Research and Statistics:
Associate Lecturer, August 2016-May 2017

Psychology Department, UWM, Milwaukee, WI

- Planed, created, and executed all aspects of the courses.

- Developed online audio and video lectures using PowerPoint addins and various screen recording and video editing software.

- Created in-class and online exercises to increase student engagement, facilitate learning, and engage students in real-world applications.

- Taught and facilitated students in designing and conducting their research projects.

- Provided extensive review and feedback for students on their research proposals and reports.

- Trained students on data entry and analysis using the SPSS and Microsoft Excel.

Courses:

- Experimental Social Psychology

- [Online] Research Methods in Psychology 
Teaching Assistant, August 2014-May 2017

Psychology Department, UWM, Milwaukee, WI

- Provided training to students on data entry and analysis using the SPSS.

- Taught discussion and lab sections for 6 graduate-level statistics classes over the course of 3 years.

- Facilitated students in the use of technology, data analysis and interpretation, as well as group exercises in an UWM active learning classroom.

- Created in-class and online exercises to increase student engagement, facilitate learning, and engage students in real-world applications.

- Led group discussions regarding course materials and related current events.

Courses:

- 3 Experimental Design, Fall 2014-Spring 2017

- 3 Advanced Psychological Statistics, Fall 2014-Spring 2017

Lecturer \& Adjunct Faculty, August 2012-May 2013

Psychology Department, SJSU, San José, CA

- Planned, created, and executed all aspects of the courses.

- Taught and facilitated students in designing and conducting their own research projects.

- Provided training to students on conducting bioassays to assess cortisol reactivity.

- Conducted writing workshops to assist students in composing their academic and research papers.

Courses:

- 2 Advanced Research Methods and Design, Fall 2012-Spring 2013.

- Psychophysiology/Neuroscience Research Laboratory, Spring 2013.

- Wrote budget and grant proposals for lab equipment (e.g., Salimetrics salivary cortisol enzyme immunoassay kits) for the assessment of neuroendocrine reactivity.

Statistics Teaching Assistant, February 2011-May 2012

Statistics Laboratory, SJSU, San José, CA

- Assisted students with questions regarding statistics and class assignments.

- Provided training to students on using the SPSS. 
Other Teaching Experience:
Teaching Assistant, August 2013-May 2014 Psychology Department, UWM, Milwaukee, WI

- Led group discussions regarding course materials and related current events.

- Created in-class and online exercises to increase student engagement, facilitate learning, and engage students in real-world applications.

- Graded assignments and exams. Courses:

- Social Psychology, Spring 2014

- [U-Pace technological-enabled instructional approach] Introduction to Psychology, Fall 2013

- Provided feedback and amplified assistance for students online.

- The U-Pace approach has received several awards (e.g., WICHE Cooperative for Educational Technologies, 2014; National University Technology Network, 2013).

Teaching Assistant, Spring 2010, January 2010-May 2010 Psychology Department, SJSU, San José, CA

- Assisted students with questions regarding the course materials.

- Graded class assignments.

- Proctored exams.

Courses: Human Learning; Clinical Psychology

Other Professional Experience:
Crisis Line Telephone Counselor, October 2008-May 2013 Contact Cares Program, Bill Wilson Center, Santa Clara, CA

- Received training and gained knowledge and skills to be a crisis line counselor.

- Provided phone counseling and referrals for callers.

- Trained and supervised new telephone counselors.

Mental Health Ambassador, August 2008-May 2011

Mental Health Ambassador Program, SJSU, San José, CA

- Conducted presentations and workshops for students and faculty to increase mental health literacy and awareness.

- Received rigorous training and gained skills, knowledge, and awareness on issues related to mental health.

- Attended weekly meetings to provide feedback and observations related to mental health issues and concerns to the Counseling and Psychological Services.

- The program received Excellence in Counseling Award from the American College Personnel Association in the $85^{\text {th }}$ annual convention. 
Campus Activity: $\quad$ Student Representative, November 2008-May 2009

Counseling and Student Health Project Advisory Committee (CASHPAC), San José, CA

- Represented SJSU students to assist the project and to provide suggestions.

- The members included SJSU architects, authorities, staff members of the Health Center and Counseling Services, and graduate students and professors working on the Kaiser Project.

- CASHPAC's goal was to develop an appropriate strategy for building a new student health and counseling facility that would enhance access of health and counseling services and address SJSU students' health care needs.

Professional Affiliations:
MPA Member, since 2014

Midwestern Psychological Association, IL

APA Member, since 2013

American Psychological Association, DC

CNS Member, since 2013

Cognitive Neuroscience Society, CA

WPA Member, since 2012

Western Psychological Association, AZ

CPA Member, since 2009

California Psychological Association, CA

Psi Chi Member, since 2008

Psi Chi Honor Society, San José, CA 